\title{
Voting in the Bicameral Congress: Large Majorities as a Signal of Quality
}

\author{
Matias laryczower* \\ Department of Politics, Princeton University \\ Gabriel Katz \\ University of Exeter \\ Sebastian Saiegh \\ Department of Political Science, UCSD
}

We estimate a model of voting in Congress that allows for dispersed information about the quality of proposals in an equilibrium context. In equilibrium, the Senate only approves House bills that receive the support of a supermajority of members of the lower chamber. We estimate this endogenous supermajority rule to be about four-fifths on average across policy areas. Our results indicate that the value of information dispersed among legislators is significant, and that in equilibrium a large fraction of House members' (40-50\%) votes following their private information. Finally, we show that the probability of a type I error in Congress (not passing a good bill) is on average about twice as high as the probability of a type Il error (passing a low-quality bill). (JEL C11, C13, D72, D78).

\section{Introduction}

One of the main arguments for bicameralism is that a bicameral legislature can improve the quality of public policy vis-à-vis a unicameral system (see (Tsebelis and Money 1997), and references therein). Evaluating the quality of proposals is indeed a key consideration in legislative settings. As numerous examples and a vast literature show (see Krehbiel 1991), two key points seem to be largely uncontroversial. First, most issues decided in Congress have a common value dimension, be it the technical merit of the proposal or its appropriateness for the given state of the environment. Second, the information about these common value components is dispersed throughout the members of Congress: no individual knows the

\footnotetext{
* Depatment of Politics, Princeton University. Email: miaryc@princeton.edu. We thank Gary Cox, Jean-Laurent Rosenthal, Matthew Shum, and seminar participants at the Universitat Autonoma de Barcelona, University of Essex, and MPSA and APSA annual meetings for comments to previous versions of this article. This article previously circulated with the title "The not-so-popular branch: bicameralism as a counter-majoritarian device."
}

The Journal of Law, Economics, and Organization, Vol. 0, No. 0 doi:10.1093/jleo/ews022 
whole truth, but each individual has some valuable information to improve the quality of legislation (Gilligan and Krehbiel 1987; Epstein and O’Halloran 1999; Londregan 1999, 2000).

With common values and dispersed information, legislators will generally be able to use the information contained in the voting decisions of other members of Congress to shape their own decision of how to vote. A natural question then emerges: Does bicameralism affect the voting behavior of members of Congress? And if so, what are the implications for policy outcomes of adopting a bicameral legislature? This article addresses these questions by analyzing roll call voting data in the U.S. Congress.

Doing so demands a new approach to the analysis of roll call voting data. Beginning with the seminal contributions of Poole and Rosenthal (1985, 1991), a large empirical literature made considerable progress in understanding the voting behavior of members of the U.S. Congress. ${ }^{1}$ This progress relied on a fully micro-founded (i.e., structural) approach, based on the sincere (nonstrategic) spatial voting model of decisionmaking in committees (SSV). In other words, these analyses take the SSV model as given, and then recover the parameters of the model as those that best fit the data.

While the SSV model has several appealing properties, it also makes strong implicit and explicit assumptions that shape the analysis and interpretation of roll call data. In particular, the SSV model assumes that the legislative setting is entirely about conflict resolution, precluding legislators from considering the technical merit or appropriateness of proposals for the given state of the environment. As a result, the SSV model rules out the possibility that bicameralism can shape the quality of public policy. ${ }^{2}$

For the same reasons, the SSV model led to a disconnection in the analysis of voting in the two chambers of Congress. In this private values model, a legislator votes in favor of a proposal if and only if the proposal is closer to her ideal policy than the status quo: the votes of other members do not contain information that would help a legislator improve her decision. In particular, legislators in one chamber cannot gain any

1. Within this framework, the literature tackled a diverse array of issues, including stability and polarization in Congress (Poole and Rosenthal 1991, 1997; McCarty et al. 2001), the role of Committees (Londregan and Snyder 1994; Poole and Rosenthal 1997), and the influence of political parties (Snyder and Groseclose 2000; McCarty et al. 2001; Cox and Poole 2002).

2. The SSV can be extended to include a publicly known valence differential between alternatives. In fact, as pointed out by Londregan (1999), the two models are equivalent: a valence advantage for the proposal against the status quo is indistinguishable from a more extreme status quo (and no valence). Thus we cannot separately identify the midpoint between two alternatives and the valence differential. Extending the spatial model to incorporate common values and dispersed information is a different matter. This is the focus of this article (see also Iaryczower and Shum, 2012a). 
relevant information by observing (or conditioning on) the outcome of the vote in the other chamber. As a result, the empirical analysis of voting in Congress treated the consideration of the same bill in the two separate chambers as statistically (and theoretically) independent.

But with dispersed information about the quality of the proposal, a bicameral legislature can amount to more than a sequence of separate chambers. If at least some members of the originating chamber use their information to guide their voting decision, the outcome of their vote will become a public signal for members of the receiving chamber. In fact, this is consistent with anecdotal evidence from comparable political institutions with two-tier committee systems. In universities, for example, votes for tenured appointments with divided support in the faculty often fail at the administration level, or are not even presented for consideration. A similar phenomenon seems to hold in committee-floor considerations in legislatures and in the courts. ${ }^{3}$

The model of common values and dispersed information suggests that this is due to the fact that the voting outcome in the originating committee aggregates information about the quality of the proposal vis-à-vis the status quo. A divided vote in an academic committee is problematic because it sends the administration a signal of low quality; similarly, a divided vote in a standing committee signals to the full membership that the proposal might be a poor response for the current state of affairs. ${ }^{4}$ Does the bicameral Congress lead to the same kind of filtering of flawed proposals as in the above examples?

We begin by establishing some key facts about the impact of bicameralism on legislative outcomes. To do so, we link the votes of bills originated in the House to their continuation in the Senate (we consider all bills that originated in the House, and whose passage in the House was decided by a roll call vote in the 102-109th Congresses; i.e., between 1991 and 2006). A basic analysis of the data makes two facts apparent. First, a large number of bills approved by the House die in the Senate. In fact, $45 \%$ of all bills passed by the House are never taken up for consideration on final passage by the Senate, and almost one quarter of all bills approved in the House reach consideration on final passage in the Senate only after

3. As (Oleszek, 2004) points out, bills "voted out of committee unanimously stand a good chance on the floor... [while a] sharply divided committee vote presages an equally sharp dispute on the floor." In their analysis of decision-making in the courts, Cross and Tiller (1998) argue that courts of appeals are more likely to follow Supreme Court doctrine when they are ideologically divided because of the potential for whistleblowing; i.e., the threat of the minority member to signal the court's disobedience to a higher court or Congress, inducing a possible reversal.

4. One might argue that it is not relevant whether the entire committee is divided, but instead whether some particular subset of the membership tends to agree or be divided about the issue. This argument, as we explain in more detail below, is not only correct but also consistent with our analysis, and simplified here only for simplicity of exposition. 
being heavily amended by that body. ${ }^{5}$ Second, the analysis illustrates a previously unknown fact. As in standing committees and universities, also in the US Congress proposals with a larger support in the originating chamber tend to be more successful in the receiving chamber.

The correlation between voting outcomes across chambers does not necessarily rule out the SSV model: any data with this property can be explained within the SSV model if the preferences of members of both chambers are properly aligned. However, we show they are not: The estimates of the SSV model that are consistent with the individual voting data generate large errors in passage rates of the same bill across chambers.

We then characterize the equilibrium voting behavior in a theoretical framework that is consistent with common values and dispersed information. In the model, a bicameral legislature considers a proposal against the status quo. The proposal is considered sequentially, first by the House and then (if it was approved) by the Senate, and has to be approved by both chambers to be enacted into law. The proposal can be of high or low quality, and individuals only have imperfect private signals about its quality. All individuals prefer a good proposal, but individuals differ in the amount of information supporting the proposal that would induce them to vote for it. We argue that the data are consistent with a particular class of equilibria of the theoretical model in which (1) only a fraction of members of the House vote informatively, and (2) the Senate only approves House bills that receive the support of an endogenous supermajority of representatives.

We estimate the model within the Bayesian framework via Markov chain Monte Carlo (MCMC) methods. The statistical model comprises two steps. In the first step, we implement a finite mixture model to estimate legislators' behavioral types and the proposal's common value component in six different policy areas. In this step, we also estimate the precision of legislators' private information. In a second step, we estimate the equilibrium cutpoint in the Senate based on the assignment of legislators into types in the first stage and on the realized vote outcome for each bill that passed the House.

The results highlight the effects of bicameralism on policy outcomes. First, our estimates imply that private information (information dispersed in the system that has not been made public and incorporated in the prior) is quite important. For one, a large fraction of the House votes according to their private information in each case (from $40 \%$ in the case of Appropriations bills, to a $50 \%$ in Judiciary bills). Moreover, the results show that the informativeness or precision of the signals is relatively large across all issue areas. Thus, large majorities are indeed informative about the quality of proposals. Second, in order to induce this degree of

5. Congressional scholars have provided anecdotal evidence suggesting that many bills passed by the House die in the Senate. A systematic and quantitative documentation of this phenomenon, however, does not appear to exist in the previous literature. 
informative voting, the Senate imposes an endogenous supermajority rule on members of the House. We estimate this supermajority rule to be about four-fifths on average across policy areas. In other words, in equilibrium bicameralism is transformed into a unicameral system with a four-fifths supermajority rule. This endogenous majority rule has significant variation across areas: close to two thirds for Foreign Relations, and larger for Economic issues (0.87) and Appropriations (0.89). Third, we show that the probability of a type I error in Congress (rejecting a high-quality bill) is on average about twice as high as the probability of a type II error (passing a low-quality bill). This is true on average across issues, and also issue by issue, with the exception of Appropriations. The discrepancy is lower in Foreign Relations and larger in Economics and Judiciary Bills.

The rest of the article is organized as follows. Section 2 reviews the related literature. Section 3 describes the main features of the data, and considers the implications of the SSV model for the passage or proposals across chambers. Section 4 introduces the theoretical model and summarizes its empirical implications. Section 5 presents the econometric specification and estimation methodology. Section 6 presents the results. Section 7 concludes and discusses possible directions for future research.

\section{Related Literature}

This article builds on an extensive literature studying the policy implications of bicameral legislatures (see (Dahl 1956; Riker 1982; Lijphart 1984; Tsebelis 1995; Tsebelis and Money 1997; and Diermeier and Myerson 1999, among many others; see also the classical analyses of Montesquieu 1748, and Hamilton et al. 1788). ${ }^{6}$

Our article focuses on what Tsebelis and Money (1997) call the efficiency rationale for bicameralism, emphasizing the importance of common values in the legislative setting (Rogers 1998, 2001). Different from previous contributions, our argument emphasizes the importance of dispersed information about the quality of proposals. As such, our analysis is connected with the literature on strategic transmission of information from specialized committees to the full chamber pioneered by Gilligan and Krehbiel (1987) and Krehbiel (1991). ${ }^{7}$ Differently than in the cheap talk models of Crawford and Sobel (1982) and Gilligan and Krehbiel (1987), the focus here is on communication through voting.

6. For a comprehensive review of this literature, see Longley and Oleszek (1989), Tsebelis and Money (1997), Cutrone and McCarty (2006), and references therein.

7. To be clear, in Gilligan and Krehbiel (1987)'s theoretical framework, legislators are uncertain about the precise mapping from policy to outcomes. However, as Hirsch and Shotts (2008) point out, "many of the examples of information and expertise in Krehbiel (1991) are better described by a model of information as policy-specific valence than by the $x=p+\omega$ model." See also Epstein and O'Halloran (1999). Moreover, with risk averse legislators, and under some conditions, reducing the uncertainty about the policy implications of a proposal is equivalent to improving its quality. 
Furthermore, an important innovation of our analysis is that we focus on the strategic considerations among members in different chambers, each of them a (multimember) committee. To do so, we build on the theoretical literature on strategic voting with common values and incomplete information (Austen-Smith and Banks 1996; Feddersen and Pesendorfer 1997, 1998) and, more specifically, on analyses dealing with strategic interactions among members of different committees (Piketty 2000; Maug and Yilmaz 2002; Razin 2003; and in particular Iaryczower 2008). ${ }^{8}$

On the methodological side, our article is related to the various contributions studying the voting behavior of members of Congress based on an underlying behavioral model. The seminal paper here is Poole and Rosenthal (1985), where-starting from the assumption that the data are generated according to the sincere voting spatial model - the authors develop NOMINATE, a method to estimate the parameters of the spatial model: legislators' ideal points and separating hyperplanes for each roll call. ${ }^{9}$ Londregan (1999) allows a (publicly known) valence advantage in the spatial voting model, and proposes to incorporate features of the process of agenda formation to deal with the incidental parameters problem present in the agnostic SSV (see also Londregan 2000; Clinton and Meirowitz 2003, 2004). Our article joins these efforts to incorporate strategic considerations into the analysis of voting in legislatures. To our knowledge, our article is the first to estimate a model of strategic voting with common values and dispersed information in a bicameral legislature (see Iaryczower et al. 2011; Iaryczower and Shum 2012a,b, for related work in the Court).

\section{Bicameralism and Legislative Outcomes}

In this section, we describe the data and document and how the sequential organization of the US Congress affects legislative outcomes. In Section 3.1 we use these data to evaluate the performance of the SSV in terms of aggregate voting outcomes.

Our data consist of all bills that were originated in the House, and whose passage in the House was decided by a roll call vote over the period 19912006 (Congresses 102 through 109). ${ }^{10}$ By bills, we refer loosely to both bills (say H.R. 100) and Joint Resolutions (say H.J.Res.100)—which have the

8. See also Cross and Tiller (1998) for a theory of minority decisions in the courts of appeals as signals to higher courts.

9. Still based on the spatial model with sincere voting, Heckman and Snyder (1997), Jackman (2001), and Clinton et al. (2004) propose alternative estimation methods. Heckman and Snyder (1997) build on the random utility model with unobservable attributes for the characteristics of the bill and the status quo. Clinton et al. (2004) develop a Bayesian procedure for the estimation and inference of spatial models of roll call voting (see also Jackman 2001).

10. In principle, it would be desirable to also include bills originated in the Senate. Unfortunately, during the period under study only a very small number of the bills originated in the Senate passed in the Senate by a roll call vote. Due to this data availability restriction, in 
same effect as bills unless they are used to propose amendments to the Constitution. We say that a bill was originated in the House if the bill was voted on final passage in the House before being voted on final passage in the Senate. We consider here only votes on final passage, thus ignoring votes on procedure or amendments. Moreover, we consider only bills that passed the House by a roll call vote, in which members' votes are recorded individually and that record is made publicly available prior to consideration of the bill in the Senate.

Under the House rules, bills are considered for approval by a simple majority vote of Representatives in a vote On Passage (OP). Bills can also be approved in the House by an alternative streamlined procedure, called Suspend the Rules and Pass (SRP). In a SRP vote, debate is restricted, amendments are not allowed, and the bill has to be approved by a two-thirds majority. Our data consist of bills considered on final passage either by a standard OP vote or by the SRP procedure. Between 1991 and 2006, 950 House bills had a roll call On Passage, and 861 had a roll call vote on SRP. ${ }^{11}$

To be considered approved by the Congress, bills need to be passed in identical form by the House and the Senate. ${ }^{12}$ Once a bill is passed by the House, its fate in the Senate can be classified in three categories. We consider that a bill passes $(P)$ if it is approved by the Senate without any amendments during the same Congressional session in which it is initiated in the House. An original bill is considered to be passed amended $(A)$ if it is approved by the Senate with amendments during the same Congressional session in which it is initiated in the House. We also consider that a bill is passed amended if it fails in the Senate by inaction, but a related bill (as classified by the Library of Congress, in Thomas) that reached the chamber's floor passed the Senate. Finally a bill fails $(F)$ if it reaches the Senate floor and is voted down, or if it is never taken up for consideration. The latter case occurs when: (a) no action whatsoever is taken in the Senate during the Congress in which the House passed the bill; (b) a bill is never reported to the Floor by the Senate committee to which it was referred; (c) the bill does not progress after being placed on the Senate's legislative calendar; or (d) the bill fails on a vote on cloture on the motion to proceed. Regardless of the particular way in which it takes place,

this article we limit our analysis to bills that originated in the House. We leave a more comprehensive analysis for future research.

11. It is worth noting that "most" bills put up for a vote on final passage in the House do in fact pass the House. Specifically, this amounted to $>90 \%$ of the 1811 votes on final passage in our database.

12. If the House and the Senate pass different versions of a bill, their disagreements are often resolved through a conference committee, an ad hoc joint committee composed of delegations of both chambers. Conferees usually draft a modified version of the bill in question, which is subsequently considered sequentially under a closed rule by the House and the Senate. Our sample includes 237 bills that were considered by the House for a final passage roll call vote after a conference committee. 


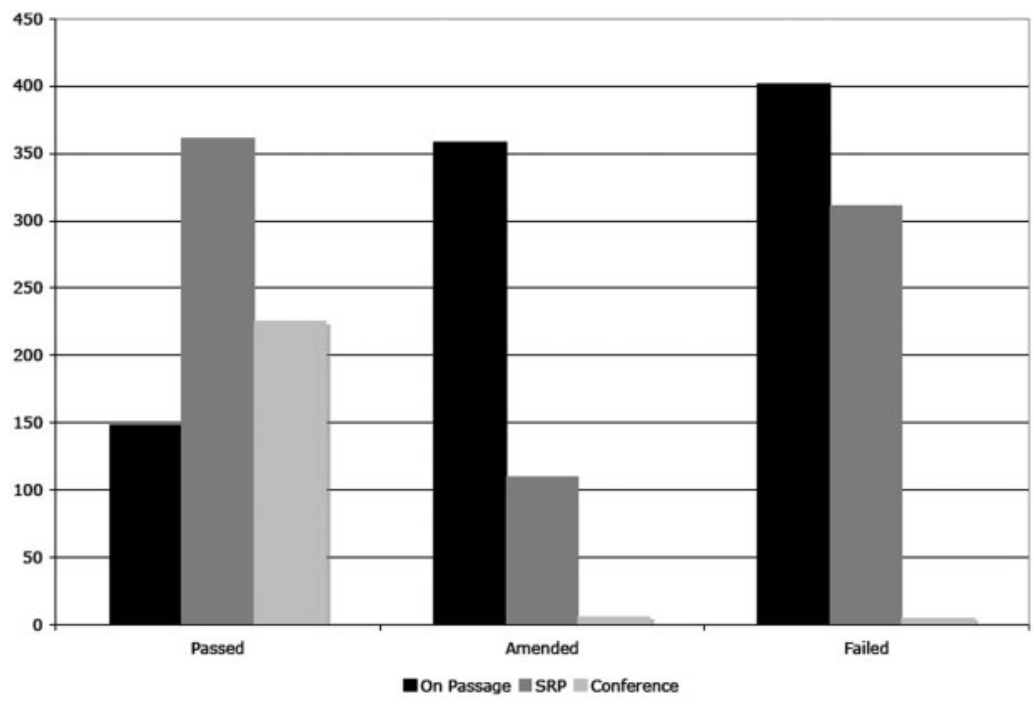

Figure 1. The Fate of House Bills in the Senate.

Senatorial inaction is akin to killing a bill. Figure 1 presents the fate of House bills in the Senate.

The figure illustrates two key points. First, a fairly significant fraction of bills that reach the Senate $(38 \%)$ do get voted in the Senate as is. Moreover, once put up for a vote, almost all of these bills in fact pass the vote in the Senate (only one in 77 bills voted by roll call and one in 432 bills voted by voice vote failed to pass). However, being up for consideration in the Senate is hardly a synonym of success. In fact, a staggering $37 \%$ (718) of the House bills that reached the Senate in the period under study were not taken up for consideration on final passage: 75 were ignored, 481 never made it out of committee, 200 were reported out of committee and put on calendar but were never voted, and 10 failed a vote to pass a filibuster. In addition, almost a quarter of the bills (475) only reached consideration for final passage after being heavily amended by the body. Thus, a second fact is that - even before considering amendmentsa large number of bills that passed the House die in the Senate. It follows that if legislators are outcome oriented and strategic, analyzing voting outcomes independently across chambers, without linking votes and outcomes to its continuation in the receiving chamber, can be problematic.

The figure has two additional implications. First, the selection of bills into OP or SRP considerations is not random or innocuous. Pieces of legislation that were approved in the House using the SRP procedure (and thus received the support of at least two-thirds of its members) were more likely to be approved without amendments by the Senate than bills approved by a simple majority (OP). The opposite is true with 
regard to those bills that were approved after being heavily amended in the Senate. House bills that were approved in the House using simple majority (OP) are more likely to be approved with amendments by the Senate than bills approved using a SRP procedure. Note also that bills approved in the House using simple majority (OP) are more likely to fail than those passed under SRP.

Second, the figure also suggests that after a bill is voted by the two chambers, and a compromise is reached within the conference committee, all private information is made public, and no uncertainty about the quality of the bill remains. In fact, there is almost no variation in outcomes after a bill is reported from the conference committee: approximately $95 \%$ of these bills (225) were passed (without amendments) once they reached the Senate. We henceforth exclude these bills from our analyses.

\section{Support for the Bill in the House: Does it Matter?}

As we mentioned in the introduction, a stylized fact about bicameral systems in various political institutions is that proposals that pass the originating committee without significant objections tend to be more successful in the receiving committee than those proposals that clear the first committee with a contested vote. Does the bicameral system in the Congress lead to similar outcomes?

To tackle this question, we begin by considering whether the outcome of the bill in the Senate is "correlated" with the fraction of members of the House supporting the bill. To measure this aggregate support, we compute the net tally of votes in favor of the proposal in the House (number of "aye" votes minus number of "nay" votes) for each bill in the sample. The upper panel of Figure 2 shows the distribution (kernel density estimates) of the net tally of votes in favor of the proposal in the House conditional on two possible outcomes in the Senate: the bill passes $(P)$ and the bill fails $(F)$.

The figure shows a significant difference in the Pass and Fail conditional distributions, especially for bills considered OP. The distribution of the tally in the House conditional on a Senate Fail (a Senate Pass) puts a relatively large probability mass on low (high) values of the tally. In other words, bills that are approved by the Senate tend to have higher tallies in the House than bills that fail in the Senate. ${ }^{13}$

The same conclusion holds if we separate bills by different policy areas. To do this, we use the committee/s to which the bill was referred to classify each roll call as pertaining to one of six policy areas: Appropriations, Foreign Relations, Economic Activity, Judiciary, Government Operations, and Others. ${ }^{14}$ The lower panel of Figure 2 shows the "Senate

13. In fact, we can say more. Bills that passed the Senate typically have higher tallies in the House than bills that pass amended in the Senate, and these in turn have higher tallies than bills that fail in the Senate.

14. We obtained the basic referral information from the Library of Congress, in Thomas. We classify a bill in "Appropriations" if it was referred to the Appropriations committee, and 

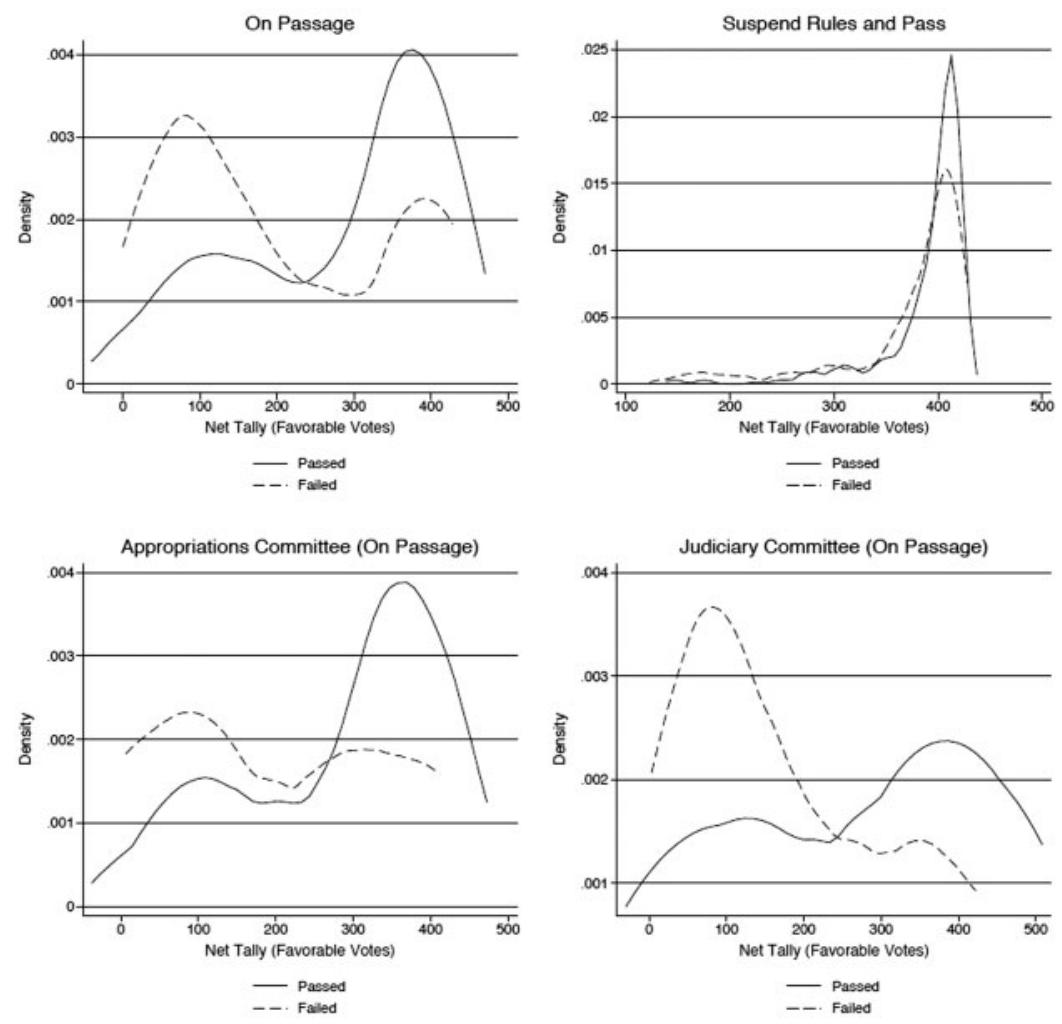

Figure 2. Tally of Votes in the House and Outcomes in the Senate.

Fail" and "Senate Pass" conditional distributions of the net tally of votes in favor of the proposal in the House for votes OP in Appropriations and Judiciary. Once again, the evidence indicates that pieces of legislation that were approved in the House with a larger net number of favorable votes are more likely to be approved by the Senate than bills approved with less legislative support.

\subsection{The Sincere Voting Spatial Model in Bicameral Perspective}

The findings in the previous section are consistent with, but do not necessarily imply that the tally of votes in the House is transmitting relevant

to "Other" if it was referred to multiple committees. If a bill was referred to a single committee other than appropriations, we classify it in one of the remaining four classes: Foreign Relations (includes Foreign Affairs, Armed Services, National Security, Veterans' Affairs, Homeland Security and Intelligence), Economic Activity (includes Agriculture, Science, Education and Labor, Energy and Commerce, Financial Services, Natural Resources, Small Business, Transportation and Infrastructure, and Merchant Marine and Fisheries), Judiciary (includes Judiciary), and Government Operations (includes Budget, Government Reform, and Ways and Means). 
information to members of the Senate. In particular, the correlation between the tally of favorable votes in the House and the outcomes in the Senate could also be consistent with the sincere voting spatial model. If the preferences of members of both chambers are correlated, then proposals that only receive the support of a small number of House members should also receive the support of a small number of Senators, while proposals that are overwhelmingly preferred to the status quo in the House should also be favored by a winning coalition in the Senate.

It should be clear, however, that the estimates of the SSV model that are consistent with the individual voting data will not necessarily be consistent with the responsiveness of the outcome in the Senate to the tally of votes in favor of the proposal in the House. For example, if preferences are perfectly aligned across chambers and both committees decide by simple majority rule, then all proposals that clear the first committee will clear the second committee as well. This, however, would be inconsistent with the passage rates described in the previous section. As a result, although not necessarily ruling out the SSV model, the correlation in voting outcomes suggest that the match between the data and the model should be reconsidered.

In this section, we evaluate this alternative hypothesis using Keith Poole's Optimal Classification (OC) common-space estimates. ${ }^{15}$ The sincere-voting spatial model is characterized by two sets of parameters. The first is the set of legislators' ideal points in the House and the Senate. Second, for each roll call, there is an associated separating line $L$, that partitions the space into two half spaces. Legislators with ideal points to either side of $L$ are predicted to vote "aye" and "nay", respectively. The basic idea is to use the separating line estimated for each roll call in the House, together with the estimates of the ideal points of Senators to obtain a predicted outcome in the Senate (see the Supplementary Appendix for details.) Having done this, we can then compare the predicted and actual outcomes in the Senate.

Figure 3 presents the comparison between the predicted outcomes generated using the $\mathrm{OC}$ estimates and the actual Senate outcomes. The top panel shows the results assuming that a simple majority rule is used to determine a bill's passage in the Senate. The bottom panel presents a similar exercise using a three-fifths majority rule, as required for cloture.

The evidence in Figure 3 shows that the standard spatial model with sincere voting generates predictions that are at odds with the data. Consider, for example, the predictions for Judiciary bills assuming that

15. OC is a nonparametric scaling method that maximizes the number of correctly classified choices (individual votes), assuming that legislators have euclidean preferences and vote sincerely. In the common-space procedure, OC is used to simultaneously scale every session of both houses of Congress, using legislators who served in both chambers to place the House and Senate in the same space. Hence, the estimates of the ideal points/roll call cutpoints are directly comparable across both chambers. These estimates are publicly available at http:// voteview.com/oc.htm. 

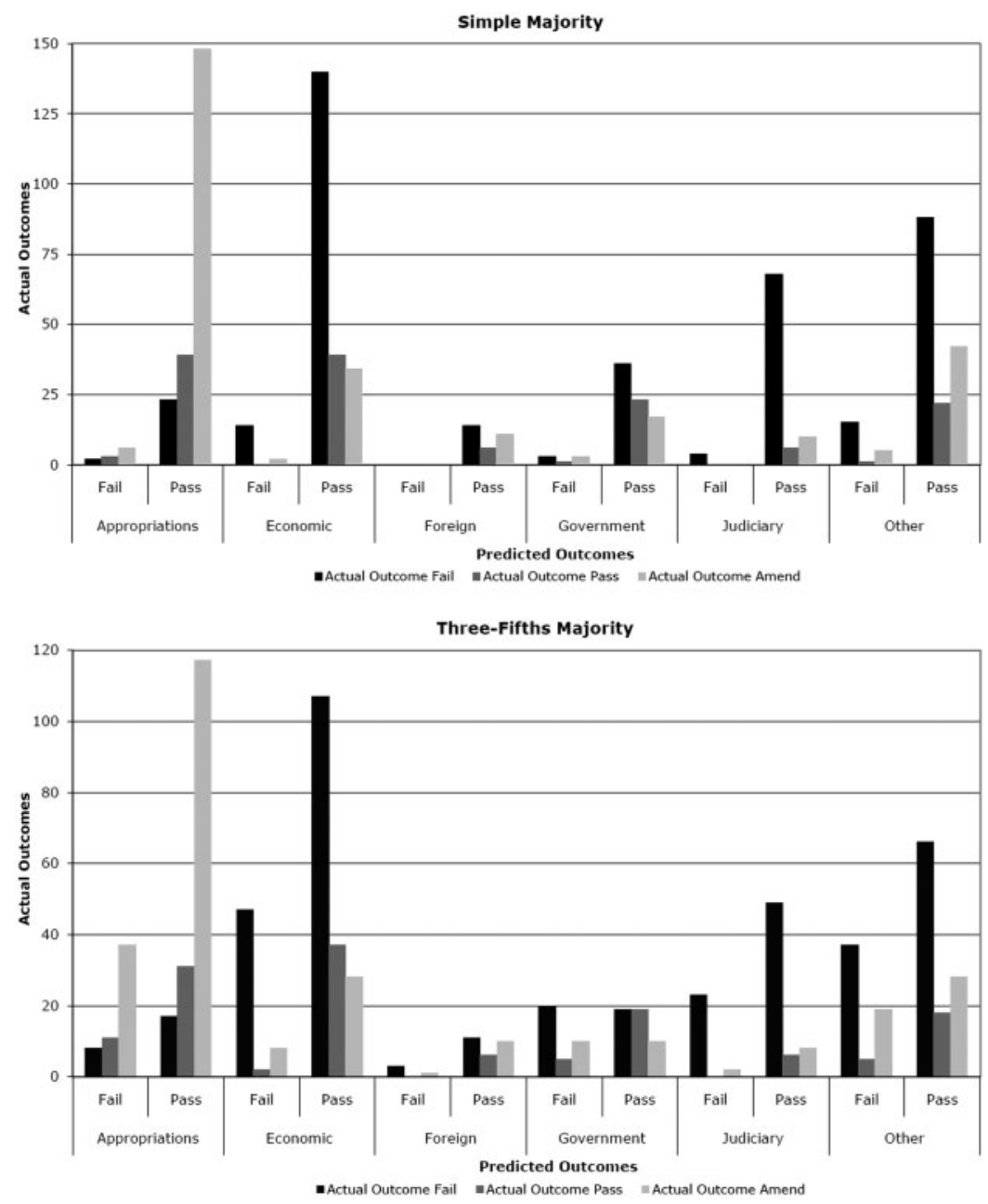

Figure 3. Actual and Predicted Outcomes in the Senate According to the SSV Model.

a simple majority voting rule is used. According to the sincere voting spatial model, 84 bills should have been approved by the Senate (and only four should have failed). Instead, 10 were approved after being heavily amended and 72 actually failed. A similar pattern holds for the other policy areas. Although the predicted power of the spatial model improves if we assume that a three-fifths majority decision rule is employed in the Senate, prediction errors are still prevalent (Figure 3). ${ }^{16}$

16. Due to the data limitations mentioned in note 10, our main analysis and estimation focuses on bills that originated in the House. However, an examination of the bills originated in the Senate shows that also in this case the SSV model generates predictions that are at odds with the data. Between 1991 and 2006, only 106 of the bills originated in the Senate were 


\section{The Model}

In this section, we present a model (introduced in Iaryczower, 2008) in which members of a bicameral legislature have dispersed information about the quality of the proposal. The model develops formally a simple intuition: if legislators have private information about the relative value of the alternatives under consideration, voting outcomes in the originating chamber can aggregate and transmit relevant information to members of the receiving chamber.

Legislators in the House $(\mathrm{H})$ and the Senate $(\mathrm{S})$ choose between a proposal $A$ and a status quo $Q$. Chamber $j=H, S$ is composed of $n_{j}$ (odd) legislators whose collective choice is determined by voting under a $R_{j}$-majority rule, $R_{j}=n_{j}+r_{j} / 2$, for $r_{j} \in\left\{1, \ldots, n_{j}\right\}$. Formally, letting $v_{i} \in\{-1,1\}$ denote $i$ 's vote against $(-1)$ or in favor (1) of the proposal, and $t\left(\mathbf{v}_{j}\right) \equiv \sum_{i \in C_{j}} v_{i}$ the net tally of votes in favor of the proposal in chamber $j$, we say that the proposal passes in chamber $j$ if and only if $t\left(\mathbf{v}_{j}\right) \geq r_{j}$. The proposal is considered sequentially by the two chambers. The alternatives are first voted on in the House. Members of the Senate observe the outcome of the vote in the House, and then vote between the two alternatives. The proposal is adopted by Congress if and only if it passes in both the House and the Senate. For simplicity of exposition, we assume here that voting is simultaneous within chamber. ${ }^{17}$

Legislators are imperfectly informed about the quality of the proposal. The proposal can be good $\left(\omega=\omega_{A}\right)$ or bad $\left(\omega=\omega_{Q}\right)$. Legislators cannot observe $\omega$, but know that $\operatorname{Pr}\left(\omega=\omega_{A}\right)=p$. Moreover, each individual $i$ in chamber $j$ receives an imperfectly informative signal $s_{i} \in\{-1,1\}$ (i.i.d. conditional on the quality of the proposal), such that $\operatorname{Pr}\left(s_{i}=1 \mid \omega_{A}\right)=$ $\operatorname{Pr}\left(s_{i}=-1 \mid \omega_{Q}\right)=q_{j}>1 / 2$. We assume moreover that the signals of members of the originating chamber are more informative than the members of the receiving chamber; and in particular that $q_{H} /\left(1-q_{H}\right) \geqslant q_{S}^{2} /\left(1-q_{S}\right)^{2}$.

Legislators' preferences have an ideological and a common value component. Each legislator $i \in C_{j}$ has a publicly known ideology bias either for or against the proposal, and we say that $i$ is either pro or anti. We denote the number of pros and antis in chamber $j$ by $\underline{m}_{j}$ and $\bar{m}_{j}$, respectively. Pros and antis differ in their ranking of alternatives conditional on observing the same information $\mathcal{I}$. In particular, pros face a cost of $\pi \in(0,1)$ if a bad proposal passes and a cost of $1-\pi$ if a good proposal does not pass, but antis face a cost of $\bar{\pi} \in(\pi, 1)$ if a bad proposal passes and a cost $1-\bar{\pi}$ if a good proposal does not pass. The payoffs for both types, if a good proposal passes or a bad proposal does not pass, is normalized to zero.

approved by a roll call vote on passage. According to the SSV model, 100 of these bills should have been approved by the House and only 6 should have failed. Instead, 53 bills actually failed, and 27 only passed the House after being amended.

17. It follows from Dekel and Piccione (2000) that the result of Proposition 1 is unchanged if voting within each chamber is sequential as well. 
Thus pros prefer the proposal to the status quo whenever $\operatorname{Pr}\left(\omega_{A} \mid \mathcal{I}\right) \geq \underline{\pi}$, whereas antis are willing to support the proposal only if $\operatorname{Pr}\left(\omega_{A} \mid I\right) \geqslant \bar{\pi}>\underline{\pi}$.

It will be convenient to measure legislators' biases in terms of the smallest number of positive House signals a legislator would need to observe for her to vote for the proposal, having observed $n$ positive Senate signals. We call these thresholds $\underline{\rho}(n)$ (for pros) and $\bar{\rho}(n)$ (for antis). We assume that $\bar{\rho}(0)>1$, and $\underline{\rho}(0)<-1$; i.e., one positive House signal is not enough to convince an anti to support the bill, whereas one negative House signal is not enough to convince a pro to vote against the bill.

\section{Strategies and Equilibrium}

A (pure) strategy for a legislator $i \in C_{j}$ is a mapping $\sigma_{i}$ from the set of signals $\{-1,1\}$ and feasible histories $\mathcal{H}_{j}$ to a vote $v_{i} \in\{-1,1\}$, with $\mathcal{H}_{H}=\emptyset$, $\mathcal{H}_{S}=\left\{\mathbf{v}_{H}: t\left(\mathbf{v}_{H}\right) \geq r_{H}\right\}$. We say that $i$ votes informatively if $\sigma_{i}\left(s_{i}, h_{j}\right)=s_{i}$ for $s_{i}=-1,1$ and $h_{j} \in \mathcal{H}_{j}$. We consider Perfect Bayesian equilibria in pure strategies, with a refinement. As the game stands, it is possible that in equilibrium members of both chambers vote for or against the proposal independently of their belief about its quality, simply because in this strategy profile their vote cannot change policy outcomes. These equilibria, however, can be nonrobust to small perturbations to the voting behavior of committee members around their equilibrium strategies. To rule out this possibility we consider the following perturbation of the game. With probability $1-v$, a committee member $i$ is a moderate, and has the preferences described above; with probability $v>0$, she is a partisan. Conditional on being a partisan, $i$ votes for (against) the proposal unconditionally with probability $\alpha$ (respectively, $1-\alpha$ ). We say that a strategy profile $\sigma(\cdot)$ is a voting equilibrium if there exists an $\bar{v}>0$ such that for all $v<\bar{v}$ there exist beliefs $\left\{\mu_{i}^{v}\left(s_{-i} \mid s_{i}, h_{j}\right)\right\}$ such that $\left(\sigma, \mu^{v}\right)$ is a Perfect Bayesian equilibrium (PBE) of the game $\Gamma_{v}$ in pure anonymous strategies. ${ }^{18}$

\subsection{Results}

For the purposes of this article, it is useful to separate equilibria of the model in two classes, according to whether the House bill can fail and succeed on a vote in the Senate with positive probability or not. Because in the data House bills are never killed on a vote in the Senate floor, we rule out equilibria of the first class as possible data-generating processes, and focus instead on equilibria in which only members of the House the originating chamber) vote informatively. ${ }^{19}$ In all equilibria with these

18. This is a relatively strong refinement, to establish the robustness of the equilibria we identify. These equilibria are also sequential, and weakly undominated. We can also consider a similar refinement to the one we propose here, in which pros (antis) can only be partisan for (against) the proposal. In this case, the requirement that $q_{H}>>q_{S}$ in the Proposition is not needed.

19. Under some conditions, there are equilibria in which members of both the originating and receiving committees vote informatively. In an equilibrium of this class, the probability that the proposal passes in the receiving committee increases (strictly) with the tally of votes in 
characteristics, members of the Senate disregard their private information, and act only to raise the hurdle that the alternative has to surpass in the House to defeat the status quo, killing the proposal following low vote tallies in the House, and unconditionally approving the proposal otherwise. ${ }^{20}$ For this reason we refer to these equilibria as endogenous majority rule equilibria (EMR).

The next proposition fully characterizes EMR voting equilibria. There are two cases, depending on whether pros have a winning coalition in the Senate (i.e., $\underline{m}_{s} \geq R_{s}$ ) or not.

\section{Proposition 1.}

1. If pros are a winning coalition in the Senate, there exists an EMR voting equilibrium if and only if $-\rho(1) \leqslant\left(\underline{m}_{H}-\bar{m}_{H}-r_{H}\right) / 2$. In equilibrium $k$ pros in the House vote informatively, and $m_{H}-k$ pros vote unconditionally for the proposal, whereas antis in the House vote unconditionally against the proposal. The proposal passes in the Senate if and only if the net tally of votes of pros voting informatively in the House is above $\rho(1)$.

2. If pros are not a winning coalition in the Senate, there exists an EMR voting equilibrium if and only if $\bar{\rho}(1) \leqslant \max \left\{\left(\bar{m}_{H}-\underline{m}_{H}+r_{H}\right) /\right.$ $\left.2-1, n_{H}-r_{H}-1+\rho(0)\right\}$. In equilibrium $k^{\prime}$ antis vote informatively, and other antis in the House vote unconditionally against the proposal, whereas pros vote unconditionally for the proposal. The proposal passes in the Senate if and only if the net tally of votes of antis voting informatively in the House is above $\bar{\rho}(1)$.

The proof of this result follows from Iaryczower (2008), and is included in the Supplementary Appendix for completeness.

To illustrate the logic driving the result, consider first a unicameral system with pure common values, with bias $\tilde{\delta} \equiv \rho(0)$. The main result of Austen-Smith and Banks (1996) is that there exists an equilibrium in which all legislators vote informatively iff $\tilde{\rho}=r$. When this is not the case, it is still possible to support a responsive equilibrium with some informative voting. This can take two forms: either a symmetric equilibrium in mixed strategies or an asymmetric equilibrium in pure strategies, in which $k$ members vote informatively. The intuition driving the result is the same in both cases. Here the number of informative votes $k$ is chosen so that for any voting member, the information provided by the

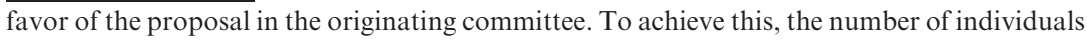
voting informatively in the receiving committee must vary following different vote tallies in the originating committee (see Iaryczower 2008).

20. Note that in equilibrium it is common knowledge for members of the Senate whether the proposal will pass in the Senate or not after observing the outcome of the vote in the House. Thus, differently to equilibria in which members of both the originating and receiving chambers vote informatively, here it is immaterial whether the proposal fails in the Senate by a vote, by scheduling, or by burying it in a Committee. 
equilibrium strategies conditional on her being pivotal exactly compensates the imbalance between the voting rule $r$ and the bias $\tilde{\rho}$. For the same reason, the number of informative votes in this equilibrium is decreasing in the difference (in absolute value) between $r$ and $\tilde{\rho}$. A similar result holds if, as it is the case in our model, we introduce two groups with different biases. The basic idea is that members not voting informatively will only act to relax or tighten the effective majority rule for individuals voting informatively.

Now consider the bicameral setting. Suppose that the Senate kills the House bill for all voting outcomes in the House in which the net tally of votes in favor of the bill is below some critical number $\theta$, and unconditionally approves the House bill otherwise. For members of the House voting informatively, this situation is equivalent to a unicameral system with a modified majority rule $\theta$. It follows that if we can induce members of the relevant decisive coalition in the Senate to choose $\theta$ so that the ensuing endogenous majority rule for individuals voting informatively in the House is equal to $\underline{\rho}(0)$ (if they are pros) or $\bar{\rho}(0)$ (if antis), these individuals would have an incentive to vote informatively in the first place. Proposition 1 shows the conditions under which this can be achieved, and provides the theoretical foundations of the econometric specification that we describe in the next section. ${ }^{21}$

\section{Estimation}

\subsection{Econometric Specification}

In EMR voting equilibria, only members of the House (the originating chamber) vote informatively. The Senate acts only to raise the hurdle that the alternative has to surpass in the House in order to defeat the status quo in equilibrium. As a result, the votes of individual members of the Senate do not provide relevant information for the econometrician. In the House, instead, all votes contain useful information to recover the structure of the model: (a) the prior probability that the quality of the proposal is high, (b) the type and strategy of each individual, and (c) the precision of their private information. The data therefore consist of an $n \times T$ matrix $v$ of voting data in the House, and a $1 \times\left(T-T_{F}\right)$ vector $z$ of outcomes of House bills in the Senate. Here, $T$ is the number of votes in which the House is the originating chamber, $T_{F}$ is the number of votes in the House in which the proposal failed in the House, and $n$ is the number of representatives. Column $t$ is therefore the voting record for all representatives in roll call $t, v_{t}$, with $i$-th entry $v_{i t} \in\{-1,1, \varnothing\}$.

21. The inference problem of members of the House voting uninformatively is different than that of members voting informatively, and (given the equilibrium refinement) introduces additional constraints to equilibrium strategies. 
Let $\alpha(\cdot)$ denote the assignment of roll calls $t=1, \ldots, T$ to issues $g=1, \ldots, G$ according to the classification in issue areas of Section 3 . We assume that the information technology - the prior probability that the bill is of high quality and the precision of legislators' private information - can differ across issues, but is invariant within issues. Legislators' preferences, and therefore ultimately the equilibrium being played, are allowed to vary both across issues and congressional sessions, but are fixed within a session of Congress and issue area.

Within each issue $g$ and Congress $c$, therefore, the preferences and voting strategy of each member of the House are fixed, and can be summarized by a behavioral type $\theta_{i g c} \in\{Y, I, N\}$. Here, $\theta_{i g c}=Y$ (respectively, $\theta_{i g c}=N$ ) denotes that in issue $g$ and legislative term $c, i$ votes unconditionally for (against) the proposal, and $\theta_{i g c}=I$ indicates that $i$ votes informatively in issue $g$ and Congress $c$, supporting the proposal when $s_{i}=1$ but voting against it when $s_{i}=-1$. The type of an individual $i$ in congressional session $c$ is therefore a $1 \times G$ vector $\theta_{i} \equiv\left(\theta_{i 1 c}, \ldots, \theta_{i G c}\right)$. Since the precision of signals is also allowed to vary by issue, $q \equiv\left(q_{1}, \ldots, q_{G}\right)$. The common prior probability that the bill is of high quality is also issue-specific. Given independence of states between roll calls, which we assume throughout, then $\operatorname{Pr}\left(\omega_{t}=\omega_{A}\right)=p_{\alpha(t)}$ and $p \equiv\left(p_{1}, \ldots, p_{G}\right)$. For each class $g$ there is also an EMR voting equilibrium cutpoint $\zeta_{g}$ in the Senate. The vector of Senate equilibrium cutpoints is then $\zeta \equiv\left(\zeta_{1}, \ldots, \zeta_{G}\right)$. Finally, we assume that there is a probability of error $\mu$ at the individual level, so that whenever equilibrium behavior dictates a vote $v \in\{-1,1\}$, the observed value is $v$ with probability $1-\mu$ and $-v$ with probability $\mu$. We can then write down an expression for the likelihood of data $y=(v, z)$ given $(q, p, \theta, \zeta)$. First,

$\operatorname{Pr}(y \mid q, p, \theta, \zeta)=\prod_{g=1}^{G} \prod_{t: \alpha(t)=g} \operatorname{Pr}\left(y_{t} \mid p_{g}, q_{g}, \theta_{g}, \zeta_{g}\right)$.

Next, given $\alpha(t)=g$, since the outcome in the Senate depends only on the relevant cutpoint $\zeta_{g}$ and on the informative tally, itself a function only of $v_{t}$ and $\theta_{g}$, we have that

$\operatorname{Pr}\left(y_{t} \mid p_{g}, q_{g}, \theta_{g}, \zeta_{g}\right)=\operatorname{Pr}\left(v_{t} \mid p_{g}, q_{g}, \theta_{g}\right) \operatorname{Pr}\left(z_{t} \mid v_{t}, \theta_{g}, \zeta_{g}\right)$.

Next we obtain an expression for $\operatorname{Pr}\left(v_{t} \mid p_{g}, q_{g}, \theta_{g}\right)$. For $a=N, I, Y$, let $m_{a}(t, g) \equiv\left|\left\{i \in C_{1}: \theta_{i}=a, v_{i t}=1\right\}\right|$ and $\ell_{a}(t, g) \equiv\left|\left\{i \in C_{1}: \theta_{i}=a, v_{i t}=-1\right\}\right|$ denote the number of individuals of type $a$ in issue $g$ voting in favor and against the bill, respectively. Now, let $\kappa_{g} \equiv\left[q_{g}(1-\mu)+\left(1-q_{g}\right) \mu\right]$ denote the probability that an individual $i$ such that $\theta_{i g c}=I$ votes in favor (against) of the proposal in roll call $t$ if $\omega_{t}=\omega_{A}$ (if $\omega_{t}=\omega_{Q}$ ). Then

$\operatorname{Pr}\left(\left\{v_{i t}\right\}_{i: \theta_{\mathrm{igc}}=I} \mid q_{g}, p_{g}\right)=\left[p_{g} \kappa_{g}^{m_{I}(t, g)}\left(1-\kappa_{g}\right)^{\ell_{I}(t, g)}+\left(1-p_{g}\right)\left(1-\kappa_{g}\right)^{m_{I}(t, g)} \kappa_{g}^{\ell_{I}(t, g)}\right]$. 
Moreover, since $\operatorname{Pr}\left(v_{i t}=1 \mid \theta_{\text {igc }}=N\right)=\mu$, and $\operatorname{Pr}\left(v_{i t}=1 \mid \theta_{\text {igc }}=Y\right)=1-\mu$, we have

$$
\begin{aligned}
\operatorname{Pr}\left(v_{t} \mid q_{g}, p_{g}, \theta_{g}\right)= & \mu^{m_{N}(t, g)}(1-\mu)^{\ell_{N}(t, g)} \times(1-\mu)^{m_{Y}(t, g)} \mu^{\ell_{Y}(t, g)} \\
& \times\left[p_{g} \kappa_{g}^{m_{I}(t, g)}\left(1-\kappa_{g}\right)^{\ell_{I}(t, g)}+\left(1-p_{g}\right)\left(1-\kappa_{g}\right)^{m_{I}(t, g)} \kappa_{g}^{\ell_{I}(t, g)}\right] .
\end{aligned}
$$

Consider now $\operatorname{Pr}\left(z_{t} \mid v_{t}, \theta_{g}, \zeta_{g}\right)$. Assume first that in the data, we observe a binary Pass/Fail outcome in the Senate $z_{t} \in\{0,1\}$, as it is in the theory. For a roll call $t$ in issue $g, \alpha(t)=g$, let $\tau_{t}\left(g, v_{t}\right) \equiv \sum_{i: \theta_{i g c}=I} v_{i}$ denote the informative tally. We introduce noise $\varepsilon_{t}$ in the class $g$ cutpoint $\zeta_{g}$ so that $z_{t}=1$ if and only if $\tau_{t}\left(g, v_{t}\right) \geq \zeta_{g}+\varepsilon_{t}$, or equivalently if $\varepsilon_{t} \leqslant \tau_{t}\left(g, v_{t}\right)-\zeta_{g}$. Assuming that $\epsilon_{t}$ is i.i.d. with c.d.f. $F(\cdot)$, then (again, for $\alpha(t)=g$ )

$$
\operatorname{Pr}\left(z_{t} \mid v_{t}, \theta_{g}, \zeta_{g}\right)=\left[F\left(\tau_{t}\left(g, v_{t}\right)-\zeta_{g}\right)\right]^{z_{t}}\left[1-F\left(\tau_{t}\left(g, v_{t}\right)-\zeta_{g}\right)\right]^{1-z_{t}} .
$$

In the data, however, we observe not two but three outcomes in the Senate: bills that Fail, bills that Pass without being amended, and bills that Pass after being amended in the Senate. In our benchmark specification, we assume that bills either Pass or Fail, but that this final outcome $z_{t} \in\{0,1\}$ is unobservable. What we observe is an imperfect signal of this final outcome, $\hat{z} \in\{P, A, F\}$, with $\operatorname{Pr}\left(\hat{z}_{t}=A \mid z_{t}=0\right)=1-\eta$, $\operatorname{Pr}\left(\hat{z}_{t}=F \mid z_{t}=0\right)=\eta, \operatorname{Pr}\left(\hat{z}_{t}=A \mid z_{t}=1\right)=1-\gamma$, and $\operatorname{Pr}\left(\hat{z}_{t}=P \mid z_{t}=0\right)=\gamma$. Then:

$$
\begin{aligned}
\operatorname{Pr}\left(\hat{z}_{t} \mid \tau_{t}\left(g, v_{t}\right), \zeta_{g}\right)= & {\left[\gamma F\left(\tau_{t}\left(g, v_{t}\right)-\zeta_{g}\right)\right]^{I\left(\hat{z}_{t}=P\right)} \times\left[\eta\left(1-F\left(\tau_{t}\left(g, v_{t}\right)-\zeta_{g}\right)\right)\right]^{I\left(\hat{z}_{t}=F\right)} } \\
& \times\left[(1-\gamma) F\left(\tau_{t}\left(g, v_{t}\right)-\zeta_{g}\right)+(1-\eta)\left(1-F\left(\tau_{t}\left(g, v_{t}\right)\right.\right.\right. \\
& \left.\left.\left.-\zeta_{g}\right)\right)\right]^{I\left(\hat{z}_{t}=A\right)}
\end{aligned}
$$

Including these additional parameters will naturally increase the model fit. To assess the robustness of our results we also estimate an alternative specification, ignoring the distinction between bills that pass $(P)$ or pass amended $(A) .^{22}$ In this alternative binary second-stage model, the dependent variable $\hat{z}$ takes the value 1 for bills that passed in the Senate-with or without amendments - and 0 for bills that failed.

22. We thank an anonymous referee for pointing us to this potential problem. In addition to the binary second-stage model, we also fit an ordered multinomial model with two cutpoints per policy area, $\zeta_{g, 1}<\zeta_{g, 2}$. The assumption here is that a bill fails in the Senate if $\tau_{t}(g$, $\left.v_{t}\right) \leqslant \zeta_{g, 1}$, is amended if $\zeta_{g, 1}<\tau_{t}\left(g, v_{t}\right) \leqslant \zeta_{g, 2}$, and passes if $\tau_{t}\left(g, v_{t}\right)>\zeta_{g, 2}$. This specification is not strictly derived from our theoretical model. However, it captures the stylized fact that bills that pass the Senate have higher tallies in the House than those amended, and these in turn have higher tallies than bills that fail in the Senate (note 13). The results of the benchmark specification are essentially unchanged. See pages 6-8 and 18-29 in the Supplementary Appendix for additional details and estimation results. 


\subsection{Estimation Methodology}

To estimate the model, we adopt a Bayesian approach. In this setting, the objects of analysis are the distributions of the parameters $(q, p, \zeta, \theta)$. We follow a two-step estimation procedure. In the first step, we use the observed votes of each legislator in each issue $g$ and Congress $c$ to estimate issue-specific posterior distributions of the signal precision $q_{g}$, the assignment of legislators into types $\theta_{\text {igc }} \in\{N, I, Y\}$, and the assignment of roll calls $t$ into high- and low-quality bills, $\left\{\omega_{Q}, \omega_{A}\right\}$. In the second step, we compute the average informative tally for each bill in issue $g$ based on the a posteriori assignment of legislators into types, and estimate the EMR equilibrium cutpoint $\zeta_{g}$. Both steps rely on MCMC methods (Gilks et al. 1996; Gelman et al. 2004). ${ }^{23}$

\section{First Stage}

The main idea underlying the estimation of the model is that the vote of legislator $i$ in a roll call $t$ depends only on her type $\theta_{i}$ and the realization of the state $\omega_{t}$ (we drop the dependence on the issue class $g$ and Congress $c$ when there is no room for confusion). From Equations (1) and (2), estimating $q$ would be straightforward if we knew the type of each legislator and the realization of the state in each roll call. The problem of course is that $\theta$ and $\omega$ are not observable. To address this complication, the first step of our estimation strategy implements a latent class, or finite mixture, model.

Latent class analysis is useful to explain heterogeneity in observed categorical variables (e.g., votes) in terms of a small number of underlying latent classes or groups (e.g., legislators' types and state realizations). The observations in the sample are assumed to arise from mutually exclusive classes characterized by intra-group homogeneity and inter-group differences in behavioral or attitudinal patterns, with the association between the observed indicators being entirely explained by their relationship to a latent categorical variable (see e.g., McLachlan and Peel 2000). In our model, these latent variables are the types $\theta$ and the state $\omega$. We then adopt an ex post specification for the state, where the state parameter is given by $\omega$ (as opposed to $p$ in an ex ante formulation). Since $\omega_{t}$ is independent across $t$, we can then estimate $p$ from the hyperparameter describing the distribution of $\omega_{t}$ (more on this below).

Compared with similar latent trait models and with traditional cluster, factor and discriminant analysis techniques, latent class models provide a simpler and more robust way of summarizing patterns of categorical responses while imposing less restrictive distributional assumptions

23. It is in fact possible to integrate both steps in a single estimation procedure. Given the complexity of the problem, however, the computational burden of a single-step estimation approach renders it very impractical for dealing with multiple large data sets, as in our case. Nonetheless, it is worth mentioning that, using small simulated data sets, we found little difference in the main substantive conclusions drawn from models estimated under the two procedures. 
(McLachlan and Peel 2000). As a result, they have recently found a growing number of uses in political science (Blaydes and Linzer 2008; Jackman 2008; Treier and Jackman 2008). Virtually all applications in the political science literature, though, assume a single relevant classification dimension.

In our setting, however, we need to classify both legislators into types and roll calls into states. To implement this, we draw on two-sided clustering methods used in collaborative filtering (Ungar and Foster 1998; Hoffman and Puzicha 1999), implementing a fully Bayesian approach based on the Gibbs sampling algorithm that allows for the (probabilistic) classification of legislators into types and roll calls into states while simultaneously estimating $q \cdot{ }^{24}$ The unknown types and states are treated as random variables with missing values, which in the Bayesian framework are essentially indistinguishable from other model parameters. Inference thus requires defining a prior for the indicators of type/state and the remaining model parameters and sampling from their joint posterior distribution.

Specifically, we proceed as follows. First, we specify a prior distribution for the parameters $\theta, \omega, q .^{25}$ In particular, we assume that (a) $q \sim U[1 / 2,1]$, that (b) for each $i \in N, \operatorname{Pr}\left(\theta_{i}=j\right)=\lambda_{j}$ for $j=N, I, Y$, and that (c) for each roll call $t \in T, \operatorname{Pr}\left(\omega_{t}=\omega_{A}\right)=p$. We give the hyperparameters $\lambda_{j}$ and $p$ diffuse prior distributions $f_{\lambda}$ and $f_{p}$. We can then write a joint posterior distribution for the vector $(\theta, \omega, q ; \lambda, p)$,

$f(\theta, \omega, q ; \lambda, p \mid v) \propto \operatorname{Pr}(v \mid \theta, \omega, q) f(\theta, \omega, q \mid \lambda, p) f_{\lambda}(\lambda) f_{p}(p)$.

Note that given $\left\{\theta_{i}\right\}$ and $\left\{\omega_{t}\right\}$, the mixture model essentially reduces to a standard binary choice model, and it is thus quite straightforward to sample from the conditional distribution of the remaining parameters. Hence, the sampling algorithm alternates two major steps (Gelman et al. 2004): (a) obtaining draws from the distribution of $\theta_{i}$ and $\omega_{t}$ given $p, \lambda$, and $q$; and (b) obtaining draws from $q$ and the hyperparameters $p, \lambda$ given the type/state realizations. This leads to an iterative scheme whereby, starting from an arbitrary set of initial values, we obtain a sample of the parameters $\psi^{m}=\left(p^{m}, \lambda^{m}, q^{m}, \theta^{m}, \omega^{m}\right)$ at each iteration $m$ of the algorithm, $m=1, \ldots, M$. Under mild regularity conditions, the

24. The standard expectation-maximization (EM) algorithm typically used to fitting latent class models cannot be efficiently formulated for this problem, since intractably many sufficient statistics are required for the EM formulation (Ungar and Foster 1998).

25. Note that this treats the voting error $\mu$ as given. In the results that we report in Section 6 , we fix this at $\mu=0.10$. All major conclusions remain unchanged if we set $\mu=0.05$. We also repeated the analysis including $\mu$ as an additional parameter to be estimated with the remaining parameters of the model. Again, the results are fundamentally unchanged. Furthermore, the estimated $\mu$ ranges between values of 0.10 and 0.15 in all policy areas. These results are reproduced in Figures 7-9 in the Supplementary Appendix. 
sampled parameters $\psi^{m}$ asymptotically satisfy $\psi^{m} \sim P\left(\psi \mid v_{g}\right)$ (Gilks et al. 1996; Gelman et al. 2004). ${ }^{26}$

Given the convergent samples, we assign each legislator to a type and each roll call to a state based on their maximum a posteriori probabilities (MAP). Given this assignment, we compute the net informative tally $\tau_{t}\left(v_{t}\right) \equiv \sum_{i: \theta_{i}=I} v_{i}$ for all bills that passed the House. Together with the outcome of the bill in the Senate, the net informative tallies computed in this way become the data in the second stage.

\section{Second Stage}

In the second step, we estimate the EMR equilibrium cutpoints $\zeta_{g}$ for $g=1, \ldots, G$. Consistent with Equation (3), we assume that the observed outcomes $\hat{z}_{t}$ are conditionally distributed $\hat{z}_{t} \sim \operatorname{Multinomial}\left(1, \varphi_{t}\right)$, with $\varphi_{t}=\left(\varphi_{t}^{P}, \varphi_{t}^{A}, \varphi_{t}^{F}\right)^{\prime}$ and, for $j=P, A, F$ :

$\varphi_{t}^{j}=\gamma_{j} P\left(z_{t}=1 \mid \tau_{t}\left(g, v_{t}\right), \zeta_{g}\right)+\eta_{j} P\left(z_{t}=0 \mid \tau_{t}\left(g, v_{t}\right), \zeta_{g}\right)$ and

$P\left(z_{t}=1 \mid \tau_{t}\left(g, v_{t}\right), \zeta_{g}\right)=\Phi\left(\tau_{t}\left(g, v_{t}\right)-\zeta_{g}\right)$

where $\gamma_{F}=\eta_{P}=0, \gamma_{A}=1-\gamma_{P}, \eta_{A}=1-\eta_{F}$, and where $\Phi$ is the cdf of a standard normal variable. In the binary second-stage model we assume

$P\left(\hat{z}_{t}=1 \mid \tau_{t}\left(g, v_{t}\right), \zeta_{g}\right)=\Phi\left(\tau_{t}\left(g, v_{t}\right)-\zeta_{g}\right)$.

\section{Prior Distributions and Model Checks}

For each step of the estimation procedure, three parallel chains with dispersed initial values and varying lengths were run after an initial burn-in period, with convergence assessed based on Gelman and Rubin's potential scale reduction factors $\widehat{R}$ (Gelman and Rubin 1992). We used independent priors for the parameters in $\psi$ : we assumed that $\lambda$ has a uniform Dirichlet distribution, that $p \sim U[0,1]$, and that $q \sim U[1 / 2,1]$. For the parameters of the second stage, we assumed $\mathcal{N}(0,100)$ distributions for $\zeta_{g}$ and, in the case of the multinomial specification (4) and (5), $\gamma, \eta \sim \operatorname{Dirichlet}(1,1)$.

Routine sensitivity checks were performed to assess the robustness of the estimates to the prior distributions. In all cases, the average overlap between the prior and posterior distributions for the parameters governing the latent class membership probabilities was quite small, and the (empirical) Kullback-Leibler divergences were extremely high. ${ }^{27}$ This indicates

26. A well-known difficulty with MCMC estimation of posterior distributions in latent class models is due to "label switching." Briefly put, the problem stems from the fact that permutations of the class assignments are not necessarily identifiable since the likelihood may be unchanged under these permutations (Redner and Walker 1984). Label switching is less of an issue in our model, given the constraints on legislators' voting behavior derived from the theoretical model. In fact, visual inspection of the MCMC chains showed no evidence of label switching, and application of the decision-theoretic postprocessing approach described by Stephens (2000) did not result in changes in the class assignments.

27. Figure 1 in the Supplementary Appendix plots the prior and posterior probability distributions of a legislator being informative, $\lambda_{I}$ and of the proposal being of high quality $p$ for three issue areas (Economic, Judiciary, and Government). The figure shows that the 
that there is enough data to distinguish between the different types and states, suggesting that the model is well identified, and thus relatively insensitive to prior assumptions (Garrett and Zeger 2000). Model diagnostics based on posterior predictive simulations (Gelman et al. 2004) showed no systematic evidence of misfits to the data and indicated that the (conditionally) independent Bernoulli distribution for legislators'votes is reasonable. In addition, in order to evaluate the ability of our estimation strategy to recover the "true" model parameters and class memberships, we used "fake-data simulations" (Gelman and Hill 2007) with several alternative data sets. Classifying legislators and roll calls according to the MAP led to very high rates of success in terms of agreement between actual and estimated class membership, and the central 95\% credible intervals for the parameters of interest covered in all cases the true values, with point estimates reasonably close to them. ${ }^{28}$

\section{Main Results}

In this section, we present our main results. For presentation purposes, we focus here on nonunanimous votes OP. ${ }^{29}$ The main results are summarized in Figure 4.

The top left panel presents the estimate of the signal precision for each issue $g, q_{g}$. The chart presents the median value, and the 5 th and 95 th percentiles of (a sample of 1000 observations drawn from) the posterior distribution of the parameters of the model. Note that the estimates in all issues are very precise, as $90 \%$ of the mass of the posterior is concentrated in a small interval around the median. In terms of the value of the estimates, note that the precision of the signals is relatively large, close to 0.9 in all issue areas. This suggests that private information-information dispersed in the system that has not been made public and incorporated in the prior - is quite important. The moderate heterogeneity across issue areas suggests that this conclusion holds independently of issue class, at least within our relatively broad issue classification.

The top right panel presents the estimate of the common prior probability that the proposal is of high quality, $p_{g} \equiv \operatorname{Pr}\left(\omega_{t}=\omega_{A} \mid \alpha(t)=g\right)$. To calculate this, we first compute for each point in the sample the proportion of roll calls with $\omega_{t}=\omega_{A}$, and then compute the median and 5-95 percentiles of this variable in the sample. The results suggest relatively moderate beliefs about the quality or appropriateness of proposals being brought to a vote in the House (possibly with the exception of the more favorable

average overlap between prior and posterior distributions is quite small. Similar patterns are verified across parameters and issue areas.

28. Details from different simulation exercises and robustness checks are available from the authors upon request. See also the Supplementary Materials.

29. Figures 4 and 5 in the Supplementary Appendix summarize the results for SRP votes. Although there are interesting differences in the details between these and bills considered $\mathrm{OP}$, the main results remain unchanged. 

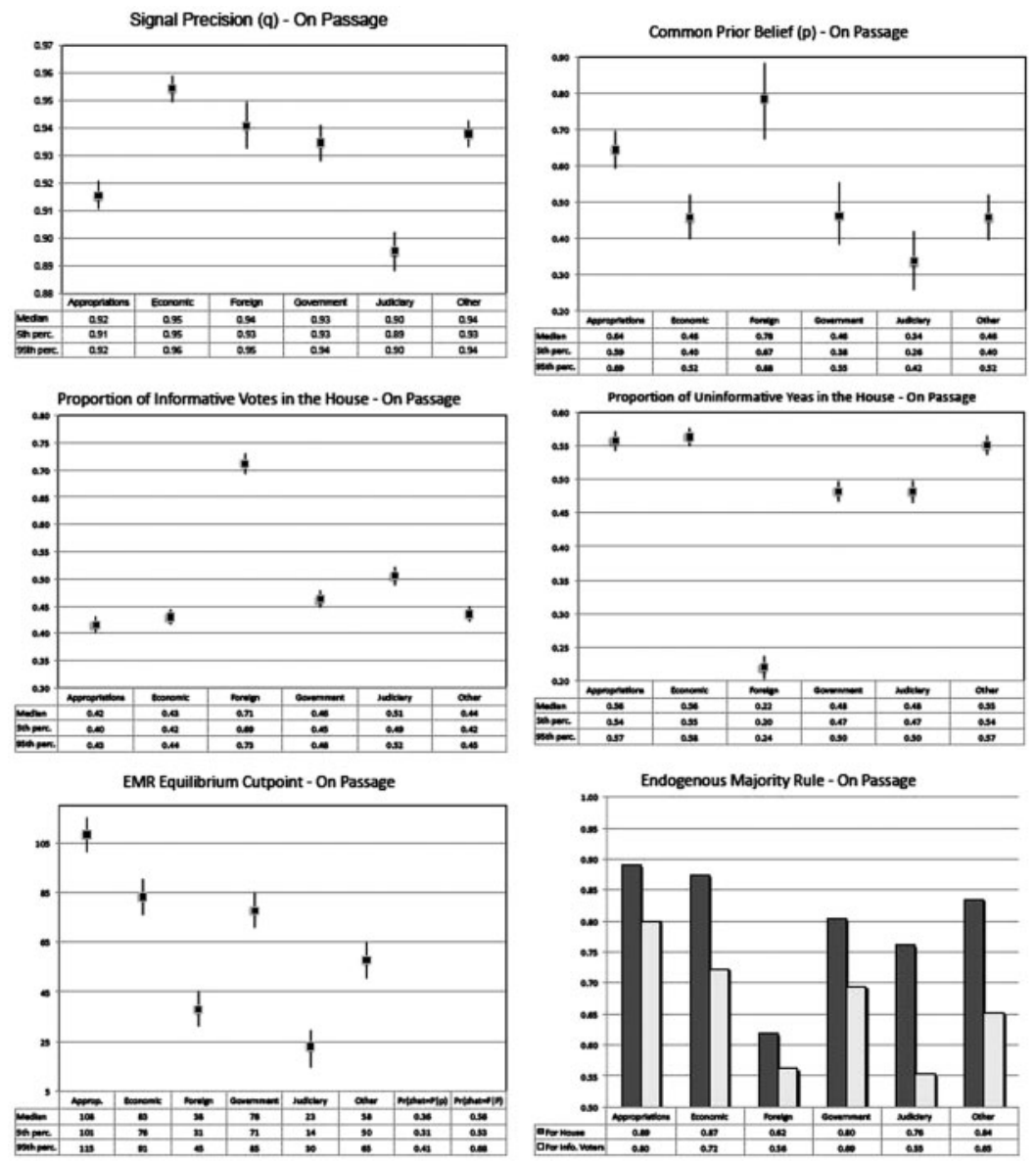

Figure 4. Precision, Prior, Distribution of Types, and Endogenous Majority Rule in Votes OP $(\mu=0.10)$.

expectations in Foreign Relations). This is consistent with our previous finding in terms of the value of private information in the system.

The middle panels show the proportion of members of the House voting informatively (left) and the proportion of members of the House voting unconditionally for the proposal (right). Recall that each point in the sample from the posterior distribution includes a type for each legislator. Thus for each point in the sample we can compute the proportion of legislators of each behavioral type. The chart presents the median, and 5-95 percentiles of this variable in the sample. The results show that, according to our estimates, a large fraction of the House votes according to their private information in each case. With the exception of Foreign Relations, the proportion of representatives voting informatively ranges from a relatively low $40 \%$ in the case of Appropriations bills, to a $50 \%$ in 
Judiciary bills. In Foreign Relations the proportion is higher still: about $70 \%$ of the total members vote informatively. The fact that this is large relative to the EMR cutpoint (lower left panel) means that the public signal generated by the informative tally of votes in favor of the proposal in the House can in fact sway the outcome in the Senate one way or the other. Moreover, most individuals that do not vote informatively vote unconditionally for the proposal; i.e., the fraction of representatives voting unconditionally against the proposal is relatively low across the different issue areas (as high as 6-7\% for Foreign Relations and Government Operations, substantially lower in all other issues).

The bottom left panel shows the EMR voting equilibrium cutpoint in the Senate, as estimated in the benchmark second-stage specification (4) and (5). This is the smallest net number of favorable votes among individuals voting informatively in the House for which the Senate passes the bill in equilibrium. The results show that these EMR cutpoints are relatively large in all areas, with a smallest value of 23 in Judiciary, and a largest value of 108 in Appropriations.

As it is implied by the name, the EMR equilibrium cutpoint effectively imposes a supermajority rule on the House, which can be computed given our estimates. Note that a cutpoint $\zeta$ means that in order for the bill to pass the Senate, we need at least $\zeta$ net votes of the members of the House voting informatively. This in turn means that if there are $n_{Y}$ partisan liberals and $n_{N}$ partisan conservatives, we need at least $\zeta+n_{Y}-n_{N}$ net votes out of all votes in total for the bill to pass the Senate $\left(n_{Y}-n_{N}\right)$ is the net uninformative tally). But this in turn means that in order for the bill to pass the Senate we need at least $\left(\zeta+n_{Y}-n_{N}+n\right) /(2)$ positive votes in total to pass the Senate. Thus, the rule for the entire chamber is $R=\left(\zeta+n_{Y}-n_{N}+n\right) /(2)$, or as a fraction of the membership,

$\frac{R}{n}=\frac{1}{2}+\frac{\zeta+n_{Y}-n_{N}}{2 n}$.

Similarly, we can compute the hurdle imposed on the set of individuals voting informatively. This effective rule for the informative voters follows quite directly from the EMR equilibrium cutpoint. A cutpoint $\zeta$ means that in order for the bill to pass the Senate, we need at least $R_{I}=\left(\zeta+n_{I}\right) /(2)$ positive votes among the $n_{I}$ members of the House voting informatively. Thus, in terms of the fraction of the total number of individuals voting informatively,

$\frac{R_{I}}{n_{I}}=\frac{1}{2}+\frac{\zeta}{2 n_{I}}$

The bottom right panel shows $R / n$ and $R_{I} / n_{I}$ for each issue area. The implied supermajority on the entire chamber is $R / n \simeq 4 / 5$ on average across areas. In other words, bicameralism is transformed in equilibrium into a unicameral system with a $4 / 5$ supermajority rule. On the other hand, 
the threshold imposed on the members voting informatively is about $R_{I} / n_{I} \simeq 2 / 3$ on average across areas. Both $R / n$ and $R_{I} / n_{I}$ have significant variation across issue areas. In particular, the EMR $R / n$ is relatively low for Foreign Relations (0.62) and largest for Economic issues (0.87) and Appropriations (0.89). Similarly, the hurdle for members voting informatively is relatively lower for Foreign Relations (0.56) and Judiciary (0.55), and largest for Economic issues (0.72) and Appropriations (0.80). ${ }^{30}$

As a robustness check, we also compute the estimated cutpoints and implied supermajority rules using the binary second-stage model (6). As seen in Figure 5, the EMR equilibrium cutpoints are similar - in magnitude and in the relative ordering of the policy areas/congressional sessions - to those obtained based on (4) and (5), although somewhat larger and more precisely estimated (due to the more parsimonious specification). The implied supermajority rules and the thresholds imposed on members voting informatively are also comparable with those reported in Figure 4 , though slightly higher. The supermajority threshold $R / n$ averages $5 / 6$ across areas and $6 / 7$ across legislative terms. Likewise, $R_{I} / n_{I} \simeq 5 / 7$ over all policy areas and $\simeq 3 / 4$ over time. Hence, the substantive conclusions regarding the equilibrium cutpoints and the effective endogenous majority rules do not seem to be especially sensitive to the parametrization of the second-stage model. ${ }^{31}$

\section{Errors and Welfare}

Although until now we have focused exclusively on the positive implications of the model, our estimates allow us to compute a measure of welfare based on the empirical frequency of type I and type II errors in Congress.

The upper panel of Figure 6 plots the sample estimates of the probability of the type I error (not passing high-quality bills), and type II error (passing low-quality bills) for votes OP across policy areas. ${ }^{32}$ The most striking result is that the probability of a type I error $\left(\varepsilon_{I}\right)$ is on average

30. The main findings discussed above hold session by session, throughout the whole period under study. Figure 2 in the Supplementary Appendix presents the signal precision (top left panel), the proportion of legislators voting informatively (top right panel), the equilibrium cutpoint (bottom left panel) and the implied supermajority rule (bottom right panel), for every Congress between 1991 and 2006. As illustrated in the figure, the estimates fluctuate much less across legislative sessions than between policy areas. The precision of the signals is higher than 0.9 in each Congress, roughly half of the House members vote informatively every term, and $R / n$ is around $4 / 5$ in all legislative sessions. The effective threshold on informative voters is also quite stable, oscillating between 0.67 (109th Congress) and 0.73 (103rd Congress).

31. It is worth noting that, based on the estimates of $\zeta, \eta$ and $\gamma$ from our benchmark second-stage specification, the posterior probability of a bill having passed the Senate given that we observe an amendment, $\operatorname{Pr}\left(z_{t}=1 \mid \hat{z}_{t}=A\right)$, averages 0.64 across policy areas. Thus we are classifying amended bills as relatively likely to have passed, which helps explain the close relationship between the results of the multinomial and binary second-stage models.

32. The estimates in SRP votes are reported in Figure 6 of the Supplementary Appendix, and the estimates for the binary and ordered second-stage models in Figures 12 and 17. These results exhibit similar patterns as in the benchmark specification. 

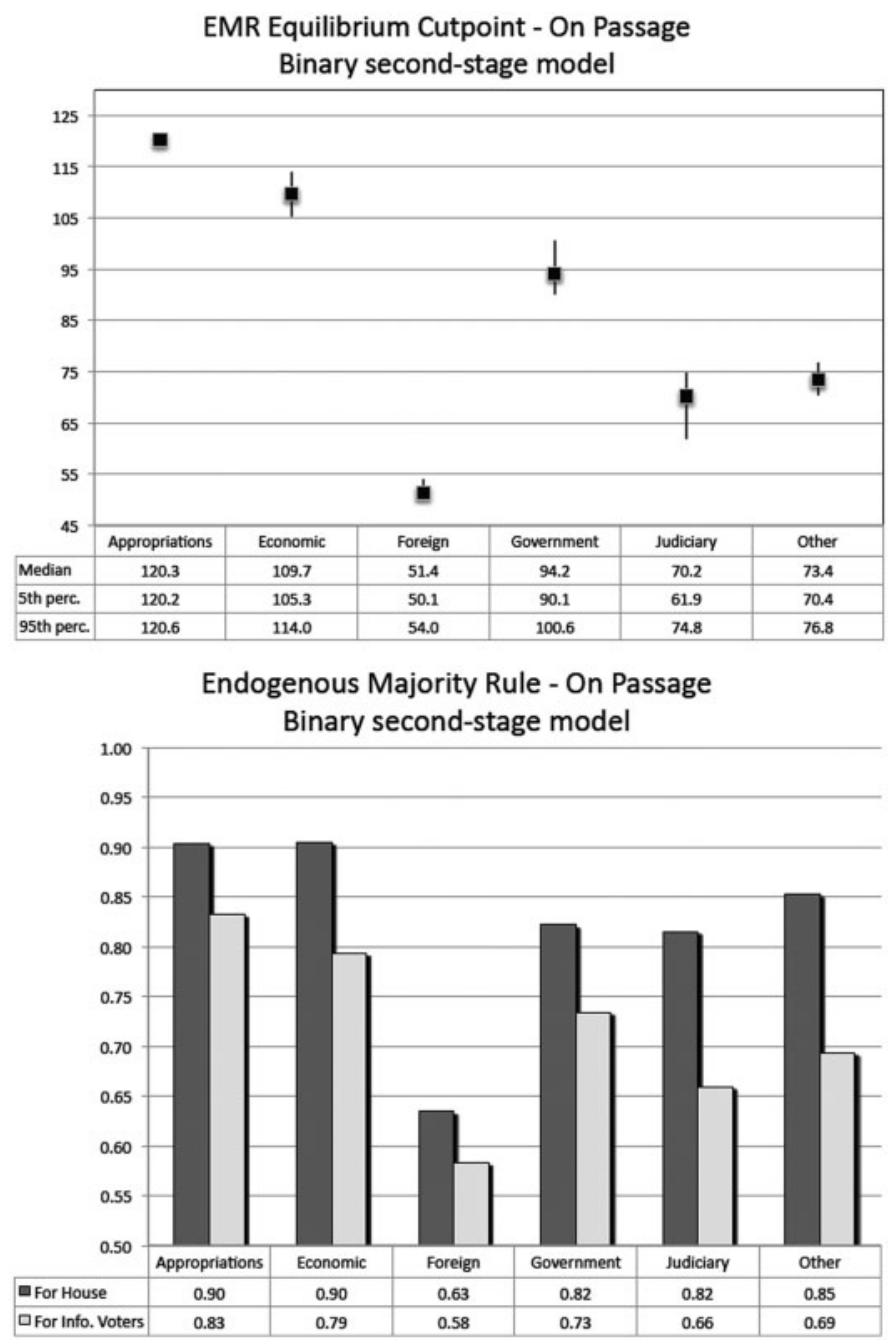

Figure 5. Equilibrium Cutpoints and Endogenous Majority Rule in Votes OP ( $\mu=0.10)$, Binary Second-Stage Model.

about twice as high as the probability of a type II error $\left(\varepsilon_{I I}\right)$. This is true on average across issues, and also issue by issue, with the exception of Appropriations. The likelihood ratio is about 1.5 in Foreign Relations, 3 in Government, and 6 in Economics. It is particularly large in Judiciary bills, where the probability of a type I error is close to $60 \%$, but the probability of a type II error is $<1 \%$.

The difference between the probability of a type I and type II error is larger in those issue areas in which the prior probability $p$ of the proposal being "good" is lower (e.g., Economic issues and Judiciary) and narrower in those with higher $p$ (such as Foreign 


\section{Empirical frequency of legislative errors - On Passage}
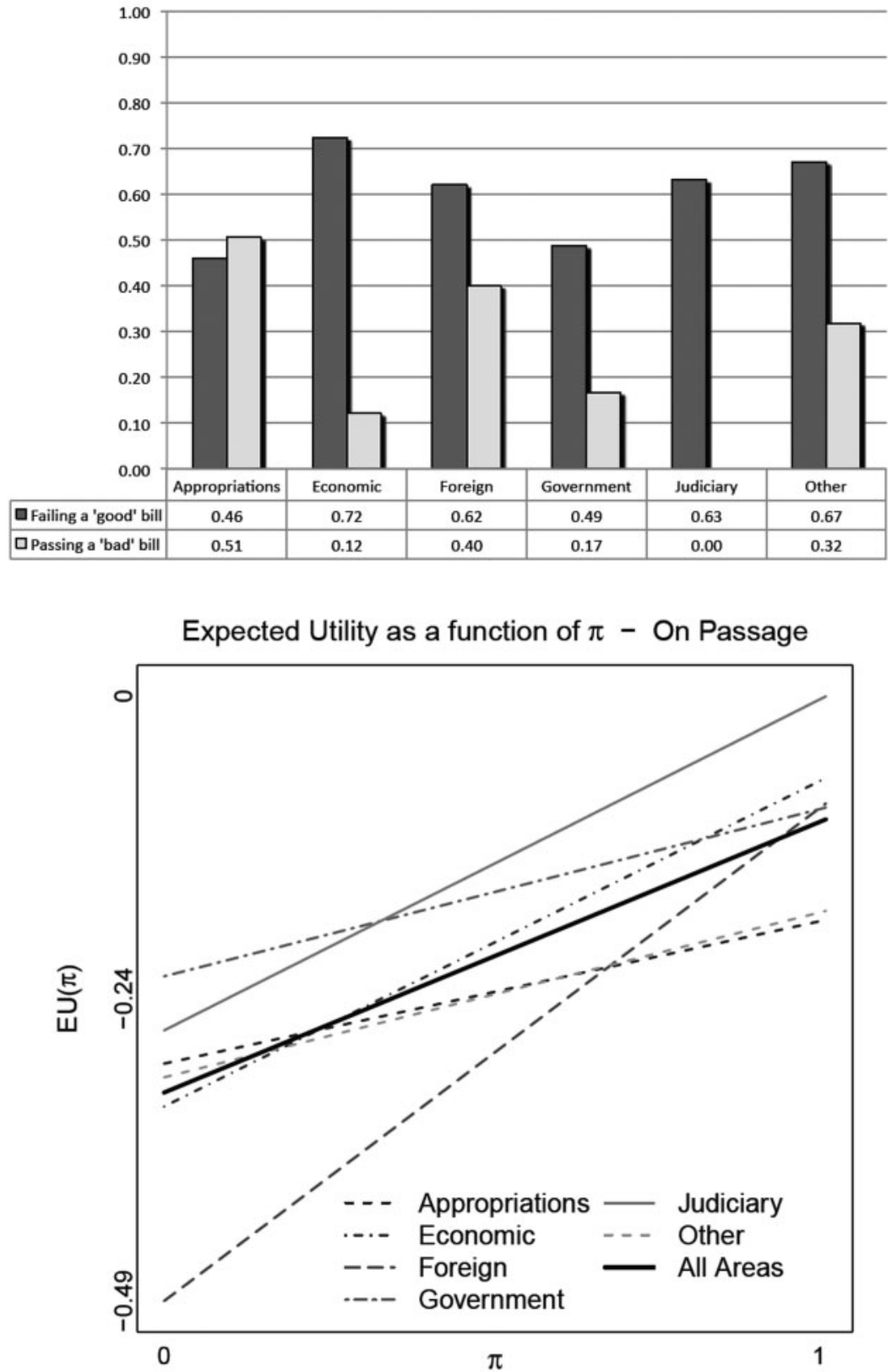

Figure 6. Empirical Frequency of Legislative Errors and Expected Utility in Votes OP $(\mu=0.10)$. 
Relations and Appropriations). Moreover, even in Appropriations, $p \times \varepsilon_{I}>(1-p) \times \varepsilon_{I I}$. Hence, the expected utility of an individual with bias $\pi, E U=-p \times \varepsilon_{I}+\pi\left[p \times \varepsilon_{I}-(1-p) \times \varepsilon_{I I}\right]$, is increasing in $\pi$ for all the policy areas under analysis. It follows that welfare is larger for more "conservative" individuals, for whom the cost of passing a bad proposal is larger (see Figure 6, lower panel). ${ }^{33}$

\section{Comparison with the Sincere Spatial Voting Model}

In Section 3.1 (Figure 3), we presented the comparison between the predicted passage of bills in the Senate implied by the spatial voting model (OC estimates) and the actual Senate outcomes. We can now extend this comparison to include our results.

Figure 7 contrasts the actual passage rates in the Senate with the predictions rates for the sequential committees model and the SSV model (assuming both a simple majority rule and a three-fifths majority rule). ${ }^{34}$ For each and every policy area, the sequential committees model clearly outperforms the SSV model under either of the voting rule in this comparison. $^{35}$ Overall, $20 \%$ of the bills in our sample were actually approved in the Senate. The average predicted passage rates for the SSV model are 95 and $78 \%$ assuming a simple majority and a three-fifths majority rule, respectively. For the sequential committees model, on the other hand, the corresponding rates are $28 \%$ under the multinomial second-stage model (4) and (5) and 36\% under the binary model (6).

What is more, the sequential committees model also fits individual votes quite well. In order to assess the performance of the model at predicting individual votes, we simulated an $n \times T$ matrix of replicated roll call votes $v^{\text {Rep }}$ from the predictive distribution $p\left(v^{\text {Rep }} \mid \psi=\widehat{\psi}\right)$, where $\widehat{\psi}$ is the vector of point estimates (posterior medians) of the parameters. ${ }^{36} \mathrm{We}$ then computed the proportion of correctly predicted individual votes, $\sum_{i, t} I\left(v_{i, t}^{\text {Rep }}=v_{i, t}\right) / n \times T$, and compared it with the value obtained from the OC estimates. The difference between both models turns out to be relatively small: the proportion of correctly predicted votes is 0.78 for the

33. An alternative interpretation of these results is that passing low-quality bills is actually the more costly mistake - i.e., the "true" type I error. The proponents of the bill thus bear the burden of proof to persuade the other legislators - especially the "conservative" membersthat the proposal is in fact "good." We thank an anonymous referee for this suggestion.

34. Figures 13 and 18 in the Supplementary Appendix reproduce this comparison using the estimates from the binary and ordered second-stage models, respectively.

35. The same is true for comparisons over time: the sequential committees model fits the data better than the SSV model for every single congressional term between 1991 and 2006. See Figures 3, 14, and 19 in the Supplementary Appendix.

36. Our Bayesian estimation actually allows generating a replicated matrix $v^{\text {Rep, } m}$ for each sample $m$ drawn from the posterior distribution of $\psi$. To enhance comparability with the predictions obtained using the OC point estimates, we report the results for a single replication generated from $p\left(v^{\text {Rep }} \mid \psi=\widehat{\psi}\right)$. Nevertheless, as shown in Figure 4, the parameters of the sequential committees model are very precisely estimated, so the substantial conclusions remain essentially unchanged when using several draws of $v^{\text {Rep }}$. 


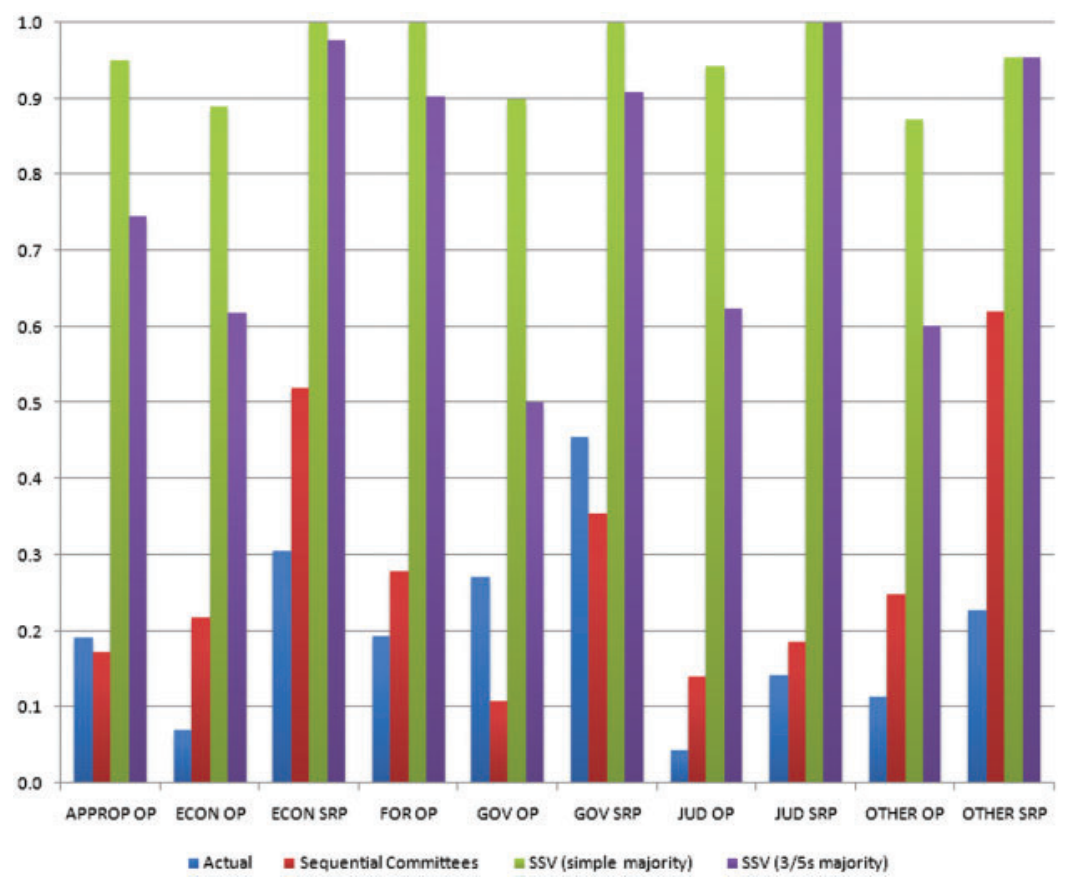

Figure 7. Actual and Predicted Passage Rates in the Senate for the Sequential Committees Model and the Spatial Voting Model.

sequential committees model and 0.81 for the SSV model. The fraction of correctly predicted votes for each legislator ranges from 0.54 to 0.97 for the sequential committees model and from 0.48 to 0.99 for the SSV model. For $95 \%$ of the legislators, both models correctly predict more than $70 \%$ of their votes.

\subsection{Do Party Labels Explain Behavior?}

Up to now, we have been agnostic about whether party labels identify the preferences and behavior of members of Congress. In particular, we chose not to assume from the outset that members of the majority party are predisposed in favor of the proposal, and members of the minority party are predisposed against the proposal.

Having said this, it is reasonable to expect that at the very least, parties will tend to bundle like-minded individuals. Thus it is interesting to see whether there is a correlation between the types we identify in the analysis and their partisan affiliation. A particular hypothesis of interest is that members of the majority party are typically biased in favor of the proposal (and thus vote unconditionally for the proposal) and that members of the minority party are typically biased against the proposal, and then either 
vote informatively or vote unconditionally against the proposal. Is this hypothesis consistent with our results?

The top panel of Figure 8 plots the proportion of members of the majority party classified as voting unconditionally for the proposal (bar) and the proportion of members of the minority party classified as voting informatively (line) per congress for Appropriations, Economic, and Other issues. The pattern here is in line with the hypothesis in the previous paragraph: although there are some notable exceptions, in most sessions and issues the individuals we classify as voting unconditionally for the proposal are (mostly) members of the majority, and the individuals that we classify as voting informatively are (mostly) members of the minority.

On the other hand, party labels are far from explaining all relevant behavior. The lower panel of the figure mimics the upper panel but for Foreign Relations, Government Operations, and Judiciary. The results are different altogether. Although there are some periods and issues for which we observe the same pattern as in the previous case, this is not the norm. Instead, in several issues/Congress observations, a majority of members of both parties vote informatively. Still in other instances, a significant fraction of the minority party votes unconditionally against the proposal. We conclude that although party labels do explain some behavior - in particular within Appropriations and Economic areasthey are generically a poor estimate for behavioral types in our model. ${ }^{37}$

More broadly - and given that the period under analysis witnessed a remarkable shift in the balance of power within the US Congress (Dodd 2001) - it is worth exploring whether and to what extent the conclusions of the sequential committees model depend on the identity of the party controlling the legislature. ${ }^{38}$ Table 1 presents the posterior medians of the relevant model parameters across all issue areas, disaggregated by the identity of the party holding a majority of the seats in the House. Overall, the results indicate that the basic findings highlighted in the previous sections remain valid regardless of which party is "in charge" namely, that information about the quality of the proposals scattered among members of the House plays an influential role in the decision-making process of the US Congress, and that a sizable proportion of them vote according to their private signals.

\section{Conclusion}

This article makes what we believe is a significant contribution to the debate about the policy consequences of adopting a bicameral legislative

37. A more detailed analysis of the role of parties in this context is left for future research.

38. Following the 1994 midterm elections, Republicans held the majority in both chambers for the first time in 40 years. Democrats would only regain control of the House and Senate in the 110th Congress. A detailed account of the "Republican Revolution" and its policy implications is beyond the scope of this article. See Dodd (2001) and the references therein for an excellent overview. 
Type Allocation by Party

(Appropriations, Economic \& Other issues)

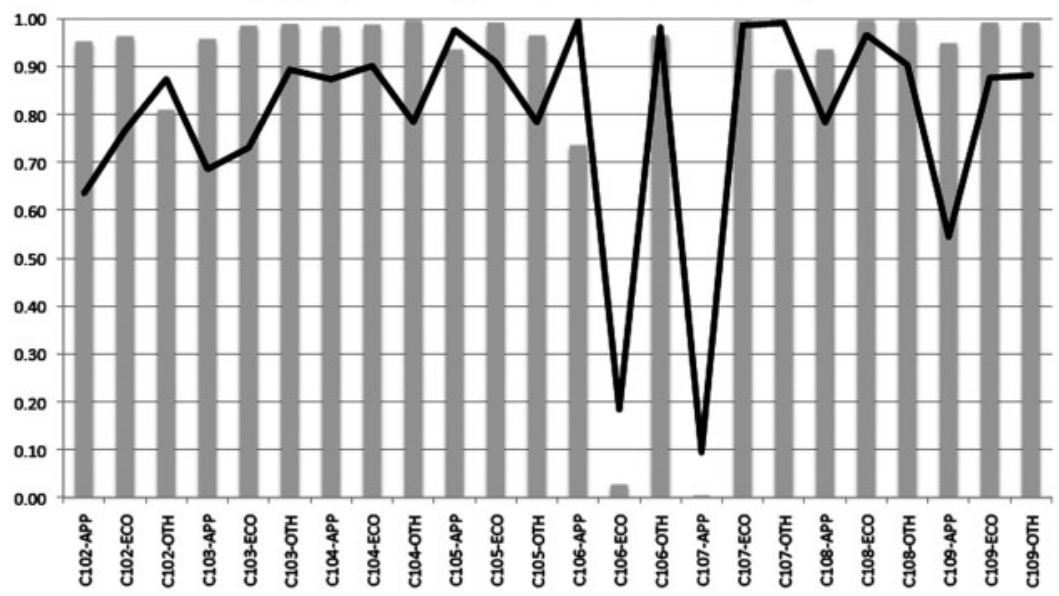

Type Allocation by Party

(Foreign Relations, Government and Judiciary)

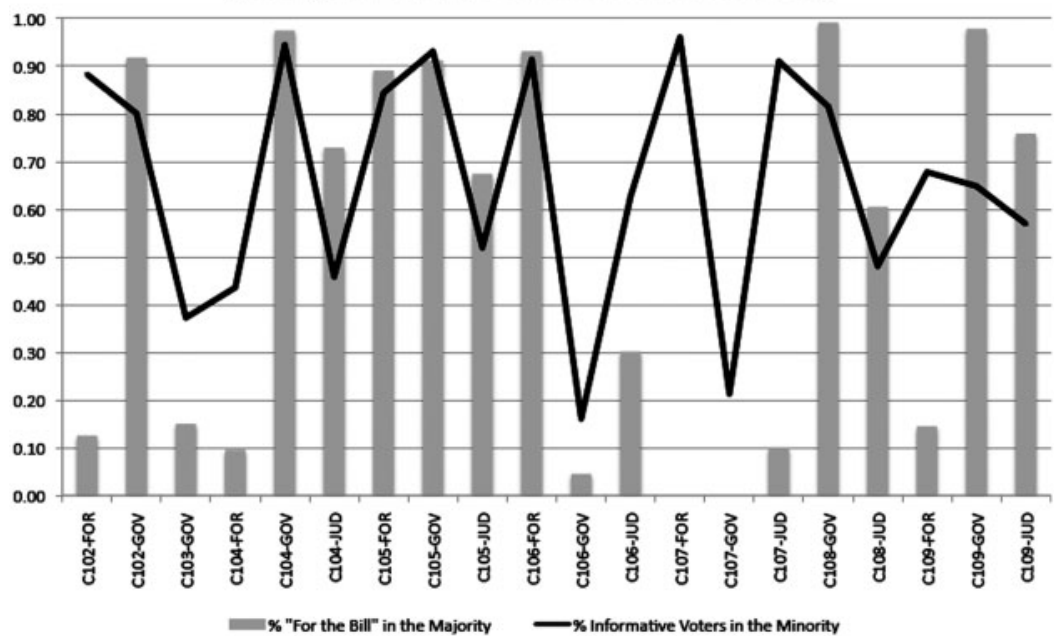

Figure 8. Proportion of Members of the Majority Party Voting Unconditionally for the Proposal, and Proportion of Members of the Minority Party Voting Informatively, by Issue Area and Congress.

Table 1. Parameter Estimates, Disaggregated by the Identity of the Majority Party

\begin{tabular}{llllll}
\hline Majority party & $q$ & $p$ & Proportion of $\theta_{i}=l$ & $R / n$ & $R / / n_{l}$ \\
\hline Democratic & 0.93 & 0.54 & 0.47 & 0.84 & 0.72 \\
Republican & 0.93 & 0.51 & 0.49 & 0.81 & 0.68 \\
All areas/Congresses & 0.93 & 0.52 & 0.48 & 0.82 & 0.69 \\
\hline
\end{tabular}


body. One set of consequences is well understood. Since at least Montesquieu (1748), bicameralism has been seen and used as a tool to represent and protect the interests of special minorities (the aristocracy, the states). Tsebelis and Money (1997) call this the political aspect of bicameralism. There is a second, equally important argument in the debate, championed by Madison in the Federalist papers (Hamilton et al. 1788). This second aspect, which Tsebelis and Money (1997) call the "efficiency" dimension of bicameralism, sees bicameralism as a tool to improve the quality of political decisions. How this happens, and to what extent does bicameralism actually enhance the quality of public policy, is less understood.

In this article, we explored the "efficiency" motivation of bicameralism. We presented a model incorporating both ideology and common values into legislative decision-making, and argued that the data are consistent with an equilibrium in which the Senate only approves the House bills that receive the support of a supermajority of members of the House. We then estimated the parameters of the model using the votes of members of the House and the Senate. We obtained three major conclusions:

(a) First, we find that private information dispersed in the system is significant. For one, a large fraction of the House votes according to their private information in each case (from $40 \%$ in the case of Appropriations bills, to a $50 \%$ in Judiciary bills). Moreover, the results show that the informativeness or precision of the signals is relatively large, above 0.8 in all issue areas and sessions of Congress.

(b) Second, we show that the endogenous supermajority imposed on the House is $R / n \simeq 4 / 5$ on average across areas and over time, a finding that is robust to alternative model specifications. In other words, bicameralism is effectively equivalent to a unicameral system with a four-fifths supermajority rule. This endogenous majority rule diverges significantly between areas: close to two-thirds for Foreign Relations, and larger for Economic issues (0.87) and Appropriations (0.89). On the other hand, there is basically no variation in the implied supermajority across congressional terms or the identity of the majority party.

(c) Third, we show that the probability of a type I error in Congress is on average about twice as high as the probability of a type II error (passing a low-quality bill). This is true on average across issues, and also issue by issue, with the exception of Appropriations. The discrepancy is lower in Foreign Relations and larger in Economics and Judiciary Bills.

This article also provides a significant methodological contribution to the analysis of voting in legislatures. To our knowledge, our article represents the first study to estimate a model of voting in bicameral legislatures that allows for common values with dispersed information in 
an equilibrium context. This complements recent efforts in the literature to incorporate strategic considerations to the analysis of voting in legislatures and courts.

In spite of the advances, much work is left for future research. Three directions are noteworthy. First, we see this article as a first step towards achieving a more general framework that can fully integrate the spatial model alongside with common value components and dispersed information. In particular, it would be desirable to allow broader heterogeneity in the biases of different individuals, as well as in the precision of their information (see Iaryczower and Shum 2012a), for a step in this direction within a single-committee setting). Second, it is also the key to refine this family of models by testing their empirical implications, and comparing their success against other possible explanations for the patterns we uncover here. Finally, we hope that this article will engage other researchers to expand the application of the framework to other legislatures and institutions around the world.

\section{Supplementaty Material}

Supplementary Material is available at Journal of Law, Economics, \& Organization online.

\section{References}

Austen-Smith, David, and Jeffrey S. Banks. 1996. "Information Aggregation, Rationality, and the Condorcet Jury Theorem," 90 American Political Science Review 34-45.

Blaydes, Lisa, and Drew A. Linzer. 2008. "The Political Economy of Women's Support for Fundamentalist Islam,” 60 World Politics 576-609.

Clinton, Joshua D., Simon D. Jackman, and Douglas Rivers. 2004. "The Statistical Analysis of Roll Call Data," 55 American Political Science Review 355-70.

Clinton, Joshua D., and Adam Meirowitz. 2003. "Integrating Voting Theory and Roll Call Analysis: A Framework," 11 Political Analysis 381-96.

_ 2004. "Testing Explanations of Strategic Voting in Legislatures: A Reexamination of the Compromise of 1790," 48 American Journal of Political Science 675-89.

Cox, Gary, and Keith T. Poole. 2002. "On Measuring Partisanship in Roll-Call Voting: The U.S. House of Representatives, 1877-1999," 46 American Journal of Political Science 477-89.

Crawford, Vincent P., and Joel Sobel. 1982. "Strategic Information Transmission," 50 Econometrica 1431-51.

Cross, Frank B., and Emerson H. Tiller. 1998. "Judicial Partisanship and Obedience to Legal Doctrine: Whistleblowing on the Federal Courts of Appeals," 107 Yale Law Journal 2155-176.

Cutrone, Michael, and Nolan McCarty. 2006. "Does Bicameralism Matter?," in B.R. Weingast, and D.A. Wittman, eds., Oxford Handbook of Political Economy Oxford: Oxford University Press.

Dahl, Robert A. 1956. A Preface to Democratic Theory Chicago, IL: University of Chicago Press.

Dekel, Eddie, and Michele Piccione. 2000. "Sequential Voting Procedures in Symmetric Binary Elections," 108 Journal of Political Economy 34-54.

Diermeier, Daniel, and Roger B. Myerson. 1999. "Bicameralism and its Consequences for the Internal Organization of Legislatures," 89 American Economic Review 1182-96. 
Dodd, Lawrence C. 2001. "Re-Envisioning Congress: Theoretical Perspectives on Congressional Change," in L.C. Dodd, and B.I. Oppenheimer, eds., Congress Reconsidered Washington, D.C: CQ Press.

Epstein, David, and Sharyn O'Halloran. 1999. Delegating Powers. A Transaction Cost Politics Approach to Policy Making under Separate Power. New York, NY: Cambridge University Press.

Feddersen, Timothy, and Wolfgang Pesendorfer. 1997. "Voting Behavior and Information Aggregation in Elections With Private Information," 65 Econometrica $1029-58$.

- 1998. "Convicting the Innocent: The Inferiority of Unanimous Jury Verdicts under Strategic Voting," 92 American Political Science Review 23-35.

Garrett, Elizabeth S., and Scott L. Zeger. 2000. "Latent Class Model Diagnosis," 56 Biometrics 1055-67.

Gelman, Andrew, John B. Carlin, Hal S. Stern, and Donald B. Rubin. 2004. Bayesian Data Analysis New York, NY: Chapman \& Hall/CRC.

Gelman, Andrew, and Jennifer Hill. 2007. Data Analysis Using Regression and Multilevel/ Hierarchical Model New York, NY: Cambridge University Press.

Gelman, Andrew, and Donald B. Rubin. 1992. "Inferences from Iterative Simulation Using Multiple Sequences," 7 Statistical Science 457-511.

Gilks, Walter R., Sylvia Richardson, and David J. Spiegelhalter. 1996. Markov Chain Monte Carlo in Practice London: Chapman \& Hall.

Gilligan, Thomas W., and Keith Krehbiel. 1987. "Collective Decision-Making and Standing Committees: An Informational Rationale for Restrictive Amendment Procedures," 3 Journal of Law, Economics and Organization 287-335.

Hamilton, Alexander, John Jay, and James Madison. 1788. The Federalist Papers. New York, NY: Penguin Books; 1987.

Heckman, James J., and James M. Snyder. 1997. "Linear Probability Models of the Demand for Attributes with an Empirical Application to Estimating the Preferences of Legislators," 28 Rand Journal of Economics S142-89.

Hirsch, Alexander V., and Kenneth W. Shotts. 2008. "Policy-Specific Information and Informal Agenda Power," Working Paper, Stanford University.

Hoffman, Thomas, and Jan Puzicha. 1999. "Latent Class Models for Collaborative Filtering Data," in T. Dean, ed., Proceedings of the 16th International Joint Conference on Artificial Intelligence San Francisco, CA: Morgan Kaufman.

Iaryczower, Matias. 2008. "Strategic Voting in Sequential Committees," HSS Working Paper 1275, California Institute of Technology.

Iaryczower, Matias, Garret Lewis, and Matthew Shum. 2011. "To Elect or to Appoint? Bias, Information, and Responsiveness of Bureaucrats and Politicians," HSS Working Paper 1323, California Institute of Technology.

Iaryczower, Matias, and Matthew Shum. 2012a. "The Value of Information in the Court: Get it Right, Keep it Tight," 102 American Economic Review 202-237.

—. 2012b. "Money in Judicial Politics: Individual Contributions and Collective Decisions," Working Paper, Princeton University.

Jackman, Simon D. 2001. "Multidimensional Analysis of Roll Call Data via Bayesian Simulation: Identification, Estimation, Inference, and Model Checking," 9 Political Analysis 227-41.

- 2008. "Measurement," in J.M. Box-Steffensmeier, H.E. Brady, and D. Collier, eds., The Oxford Handbook of Political Methodology. New York, NY: Oxford University Press.

Krehbiel, Keith. 1991. Information and Legislative Organization. Ann Arbor, MI: University of Michigan Press.

Lijphart, Arend D. 1984. Democracies: Patterns of Majoritarian and Consensus Government in Twenty-One Countries. New Haven, CT: Yale University Press.

Londregan, John B. 1999. "Estimating Legislators' Preferred Points," 8 Political Analysis $35-56$. 
2000. Legislative Institutions and Ideology in Chile. New York, NY: Cambridge University Press.

Londregan, John B., and James M. Snyder. 1994. "Comparing Committee and Floor Preferences," 19 Legislative Studies Quarterly 233-266.

Longley, Lawrence D., and Walter J. Oleszek. 1989. Bicameral Politics. Conference Committees in Congress. New Haven, CT: Yale University Press.

Maug, Ernst, and Bilge Yilmaz. 2002. "Two Class Voting: A Mechanism for Conflict Resolution," 92 American Economic Review 1448-71.

McCarty, Nolan, Keith T. Poole, and Howard Rosenthal. 2001. "The Hunt for Party Discipline in Congress," 95 American Political Science Review 673-87.

McLachlan, Geoffrey J., and David Peel. 2000. Finite Mixture Models New York, NY: Wiley \& Sons.

Montesquieu, Charles. 1748. The Spirit of Laws. Amherst, MA: Prometheus Books. 2002.

Oleszek, Walter J. 2004. Congressional Procedures and the Policy Process. Washington, D.C.: CQ Press.

Piketty, Thomas. 2000. "Voting as Communicating," 67 Review of Economic Studies 169-191.

Poole, Keith T., and Howard Rosenthal. 1985. "A Spatial Model for Legislative Roll Call Analysis," 29 American Journal of Political Science 357-84.

- 1991. "Patterns of Congressional Voting," 35 American Journal of Political Science 228-78.

1997. Congress. A Political-Economic History of Roll Call Voting. New York, NY: Oxford University Press.

Razin, Ronny. 2003. "Signaling and Election Motivations in a Voting Model with Common Values and Responsive Candidates," 71 Econometrica 1083-119.

Redner, Richard A., and Homer F. Walker. 1984. "Mixture Densities, Maximum Likelihood and the EM Algorithm," 26 SIAM Review 195-239.

Riker, William H. 1982. Liberalism versus Populism. San Francisco, CA: W.H. Freeman.

Rogers, James R. 1998. "Bicameral Sequence. Theory and State Legislative Evidence," 42 American Journal of Political Science 1025-60.

- 2001. "An Informational Rationale for Congruent Bicameralism," 13 Journal of Theoretical Politics 123-51.

Stephens, Matthew. 2000. "Dealing with Label Switching in Mixture Models," 62 Journal of the Royal Statistical Society: Series B 795-809.

Snyder, James M., and Tim Groseclose. 2000. "Estimating Party Influence in Congressional Roll-Call Voting," 44 American Journal of Political Science 193-211.

Treier, Shawn, and Simon D. Jackman. 2008. "Democracy as a Latent Variable," 52 American Journal of Political Science 201-17.

Tsebelis, George. 1995. "Decision Making in Political Systems: Veto Players in Presidentialism, Parlamentarism, Multicameralism, and Multipartyism," 25 British Journal of Political Science 289-325.

Tsebelis, George, and Jeannette Money. 1997. Bicameralism. New York, NY: Cambridge University Press.

Ungar, Lyle H., and Dean P. Foster. 1998. "A Formal Statistical Approach to Collaborative Filtering," Presented at the Conference on Automated Learning and Discovery; Carnegie Mellon University, Pittsburgh, June 1998. 